\title{
A systematic review of cerebral microdialysis and outcomes in TBI: relationships to patient functional outcome, neurophysiologic measures, and tissue outcome
}

\author{
Frederick A. Zeiler ${ }^{1,2,3}$ - Eric Peter Thelin ${ }^{4,5}$ - Adel Helmy ${ }^{4}$ Marek Czosnyka ${ }^{4,6}$. \\ Peter J. A. Hutchinson ${ }^{4}$. David K. Menon ${ }^{3,7,8,9}$
}

Received: 3 April 2017 / Accepted: 19 September 2017 / Published online: 7 October 2017

(C) The Author(s) 2017. This article is an open access publication

\begin{abstract}
Objective To perform a systematic review on commonly measured cerebral microdialysis (CMD) analytes and their association to: (A) patient functional outcome, (B) neurophysiologic measures, and (C) tissue outcome; after moderate/severe TBI. The aim was to provide a foundation for next-generation CMD studies and build on existing pragmatic expert guidelines for CMD.
\end{abstract}

\section{PJA Hutchinson and DK Menon are joint senior authors.}

This article does not contain any original research studies with human participants or animals performed by any of the authors. It only summarizes previously published research in the field of microdialysis.

Electronic supplementary material The online version of this article (https://doi.org/10.1007/s00701-017-3338-2) contains supplementary material, which is available to authorized users.

Frederick A. Zeiler

umzeiler@myumanitoba.ca

Eric Peter Thelin

eric.thelin@ki.se

Adel Helmy

adelhelmy@doctors.net.uk

Marek Czosnyka

mc141@medschl.cam.ac.uk

Peter J. A. Hutchinson

pjah2@cam.ac.uk

David K. Menon

dkm13@cam.ac.uk

Section of Neurosurgery, Department of Surgery, Rady Faculty of Health Sciences, University of Manitoba, Winnipeg, MB R3A 1R9, Canada
Methods We searched MEDLINE, BIOSIS, EMBASE, Global Health, Scopus, Cochrane Library (inception to October 2016). Strength of evidence was adjudicated using GRADE.

Results (A) Functional Outcome: 55 articles were included, assessing outcome as mortality or Glasgow Outcome Scale (GOS) at 3-6 months post-injury. Overall, there is GRADE $\mathrm{C}$ evidence to support an association between CMD glucose,

2 Clinician Investigator Program, University of Manitoba, Winnipeg, Canada

3 Department of Anesthesia, Addenbrooke's Hospital, University of Cambridge, Cambridge, UK

4 Division of Neurosurgery, Department of Clinical Neurosciences, University of Cambridge, Cambridge Biomedical Campus, Cambridge CB2 0QQ, UK

5 Department of Clinical Neuroscience, Neurosurgical Research Laboratory, Karolinska University Hospital, Building R2:02, Karolinska Institutet, S-17176 Stockholm, Sweden

6 Section of Brain Physics, Division of Neurosurgery, University of Cambridge, Cambridge CB2 0QQ, UK

7 Neurosciences Critical Care Unit, Addenbrooke's Hospital, Cambridge, UK

8 Queens' College, Cambridge, UK

9 National Institute for Health Research, Southampton, UK 
glutamate, glycerol, lactate, and LPR to patient outcome at 36 months. (B) Neurophysiologic Measures: 59 articles were included. Overall, there currently exists GRADE C level of evidence supporting an association between elevated CMD measured mean LPR, glutamate and glycerol with elevated ICP and/or decreased CPP. In addition, there currently exists GRADE C evidence to support an association between elevated mean lactate:pyruvate ratio (LPR) and low $\mathrm{PbtO}_{2}$. Remaining CMD measures and physiologic outcomes displayed GRADE D or no evidence to support a relationship. (C) Tissue Outcome: four studies were included. Given the conflicting literature, the only conclusion that can be drawn is acute/subacute phase elevation of CMD measured LPR is associated with frontal lobe atrophy at 6 months.

Conclusions This systematic review replicates previously documented relationships between CMD and various outcome, which have driven clinical application of the technique. Evidence assessments do not address the application of CMD for exploring pathophysiology or titrating therapy in individual patients, and do not account for the modulatory effect of therapy on outcome, triggered at different CMD thresholds in individual centers. Our findings support clinical application of CMD and refinement of existing guidelines.

Keywords Cerebral microdialysis · Systematic review · Patient outcome $\cdot$ Functional outcome

\section{Introduction}

Cerebral microdialysis (CMD) has seen broad application across neurocritical care $[19,24,46]$. By sampling brain parenchymal extracellular fluid, CMD provides insights into cellular metabolism and injury to guide clinical therapy, and provide characterization of the host response (currently only as a research tool) during pathologic states. To date, the largest application of CMD is within the traumatic brain injury (TBI) population $[19,46]$.

Commonly measured CMD analytes include: glucose, lactate, pyruvate, (allowing calculation of the lactate:pyruvate ratio (LPR)), glutamate, glycerol as well as the cations sodium and potassium $[41,49,50]$ (although the common presence of these cations in the dialysis fluid makes their measurement challenging). Other potential candidate biomarkers can be measured from CMD samples, and an expanding panel includes immune cytokines and other biomolecules [35, 36]. However, these latter analytes are measured offline and do not currently impact clinical practice.

Despite the wide application of CMD in TBI in neurointensive care units (NICUs), the technique is still developing, and the evidence base supporting its optimal use evolving. Published expert consensus statements on the application of multi-modal intracranial monitoring in general, and microdialysis in particular, support the use of CMD as part of a multi-modality panel [41, 49, 50]. These consensus statements summarize key publications and provide a pragmatic approach to the use of CMD based on collective current experience. Critically, much of this advice has been based on outcome associations of monitored variables. However, there has been no detailed systematic review of the literature using standard evidence evaluation methodology.

The absence of such a review is unsurprising for several reasons. First, the studies are heterogenous, and with a few exceptions, involve small patient numbers. Second, intervention thresholds based on microdialysis monitoring in these studies vary substantially, and the consensus achieved in recent publications has not been universally applied in the past. Finally, despite the outcome associations that have been demonstrated, any impact of a monitoring technique on outcome will critically depend on the interventions that it triggers, and these are both highly variable between centers, and generally poorly described in the available literature. Consolidation of the evidence base for optimal use of CMD may require a new generation of studies, which couples the best estimate of critical monitoring thresholds identified by expert opinion and physiological principles with standard approaches to data collection and outcome assessment.

Critically, this new generation of studies will need a framework for protocols that complies with quality metrics that underpin evidence-based medicine. The development of such a framework is dependent on a robust review of the available literature, not just summarizing the evidence, but also identifying whether and how a subsequent generation of studies can be designed to provide further high-quality evidence to underpin clinical practice. We have therefore undertaken a rigorous systematic review of the available literature addressing three key questions:

- Do commonly measured CMD analytes display an association with patient functional outcome?

- Are these analytes associated with specific neurophysiologic changes seen during NICU care?

- Are these analytes associated with tissue outcome on imaging (such as acute ischemia/infarct, or atrophy long term)?

\section{Methods}

A systematic review was conducted using the methodology outlined in the Cochrane Handbook for Systematic Reviewers [37]. Data were reported following the Preferred Reporting Items for Systematic Reviews and Meta-Analyses (PRISMA) [59]. The review questions and search strategy 
were decided upon by the primary author (FAZ) and supervisors (AH and DKM).

\section{Search question, population, inclusion and exclusion criteria}

The questions posed for this systematic review were:

1. Do commonly measured CMD analytes have an association with patient functional outcome in moderate and severe $\mathrm{TBI}$ ?

2. Do commonly measured CMD analytes have an association with neuro-physiologic measures in moderate and severe TBI?

3. Do commonly measured CMD analytes have an association with tissue outcome/tissue fate in moderate and severe $\mathrm{TBI}$ ?

The CMD analytes that we included in the "commonly measured" category included: glucose, lactate, pyruvate, LPR, potassium, sodium, glutamate, and glycerol. All studies of five patients or more were included.

\section{Functional outcome - outcome measures and primary/secondary outcomes}

The primary outcome measure was: documented association between one of the CMD measures and patient outcome. Any outcome score or mention of morbidity/mortality within the studies was deemed acceptable. Secondary outcome measures were: complications associated with CMD monitoring.

\section{Neuro-physiologic measures - outcome measures and primary/secondary outcomes}

The physiologic parameters of interest were: ICP, CPP, $\mathrm{PbtO}$, cerebral physiology and metabolism assessed using PET, autoregulatory capacity (measured by any technique), and CBF (assessed by any technique). All studies of five patients or more were included. The primary outcome measure was: documented association between one of the CMD measures and one of the mentioned neuro-physiologic measures. Secondary outcome measures were: complications associated with CMD monitoring.

Tissue outcome - outcome measures and primary/secondary outcomes

The tissue outcome of interest was ischemia/infarction during acute/subacute hospital stay, primary lesion expansion during acute/subacute stay, and cortical atrophy as assessed during long-term follow-up imaging. Imaging studies deemed appropriate endpoints for association with CMD variables were computed tomography (CT), magnetic resonance imaging (MRI)/magnetic resonance spectroscopy (MRS), and a subset of positron emission tomography (PET) studies (see below). All studies of five patients or more were included. The primary outcome measure was: documented association between one of the CMD measures and tissue outcome. Secondary outcome measures were: complications associated with CMD monitoring.

\section{General inclusion/exclusion criteria}

Inclusion criteria were: All studies including human subjects with moderate or severe TBI (GCS of 12 or less), studies with five or more patients, any age category, the use of CMD to measure "common" analytes (glucose, lactate, pyruvate, LPR, glutamate, glycerol) as well as potassium and sodium, and documentation of either: (A) patient functional outcome in relation to CMD measures, (B) documentation of neurophysiologic metrics in relation to CMD analytes, (C) the use CMD to measure "common" analytes (glucose, lactate, pyruvate, LPR, glutamate, glycerol), and documentation of tissue outcome in relation to CMD measures.

Exclusion criteria were: Non-English studies, animal studies and studies of less than five patients. Non-English studies were excluded given the small number identified. For the "tissue outcome" portion of the review, positron emission tomography (PET) tissue assessments based on ${ }^{15} \mathrm{O}$ PET or $\left[{ }^{18} \mathrm{~F}\right]$ FDG PET were excluded due to the fact that these imaging modalities assess neurophysiologic parameters such as metabolism and cerebral blood flow (CBF), not tissue outcomes such as ischemia/infarction or cortical volume loss. However, we sought to include PET studies that related CMD variables to PET ligands that mapped survival of neuronal populations at follow up (e.g., $\left[{ }^{11} \mathrm{C}\right]$ flumazenil PET and GaBAergic neurons).

\section{Search strategy}

MEDLINE, BIOSIS, EMBASE, Global Health, SCOPUS, and Cochrane Library from inception to October 2016 were searched using individualized search strategies. The search strategy for MEDLINE can be seen in Appendix A of the supplementary material, with a similar search strategy utilized for the other databases.

In addition, we surveyed relevant meeting proceedings for the last 5 years for ongoing and unpublished work based on CMD in moderate-to-severe TBI patients. The meeting proceedings of the professional societies that were searched can be seen in Appendix A of the Supplementary materials.

Finally, reference lists of any review articles on CMD were searched for relevant studies on CMD. 


\section{Study selection}

Two reviewers undertook a two-step review of all articles returned by our search strategies, separately for each review question resulting in three separate systematic reviews.

First, reviewers independently (FZ and ET) screened titles and abstracts of the returned articles to decide if they met inclusion criteria. Second, full text of the chosen articles were then assessed to confirm if they met the inclusion criteria and that the primary outcome of patient functional outcome was reported in the study (FZ and ET). Any discrepancies between the two reviewers were resolved by a third reviewer if needed (AH or DKM).

\section{Data collection}

Data were extracted from the selected articles and stored in an electronic database. Data fields included: patient demographics, type of study, article location, number of patients, CMD analyte measured, CMD measurement details (probe tissue location, sampling frequency), outcome measure utilized (outcome score, neuro-physiologic variable measured, tissue outcome assessment technique etc.), association of CMD measure to outcome (functional, neuro-physiologic, or tissue), and complications to CMD.

\section{Bias assessment}

Two reviewers (FZ and RT) used the RTI item bank [102] to assess bias in each study, with each component item graded as Low-risk, High-risk, or Unclear. Discrepancies resolved by discussion and a third party if needed (AH or DKM). This bias assessment was repeated for each question of interest, as there was some overlap in the articles between the review on patient functional outcome and neuro-physiologic measures. Appendix B in the Supplementary Material provides a table outlining details of risk assessment.

\section{Quality of evidence assessment}

Each reviewer (FZ and ET) used the Grading of Recommendation Assessment Development and Education (GRADE) criteria [30-33, 43, 85] to assess the level of evidence for each CMD substrate and: (A) functional outcome, (B) neuro-physiologic measure, (C) tissue outcome. Final GRADE level was determined via consensus amongst the group of authors.

The GRADE level of evidence is split into four levels: A, B, C, and D. GRADE level A represents high evidence with multiple high-quality studies having consistent results. GRADE level B represents moderate evidence with one high-quality study, or multiple low-quality studies. GRADE level $\mathrm{C}$ evidence represents low evidence with one or more studies with severe limitations. Finally, GRADE level D represents very low evidence based on either expert opinion or few studies with severe limitations.

\section{Statistical analysis}

A meta-analysis was not performed in this study due to the heterogeneity of data and study design within the articles identified.

\section{Results}

\section{Search strategy results}

The PRISMA flow diagrams showing the search strategy is available in Appendix A of the Supplementary materials. Overall, 2739 articles were identified, with 2716 from the database search and 23 from published meeting proceedings. There were 1590 duplicates removed, leaving 1149 references to review. Application of inclusion/exclusion criteria to the title and abstract of these articles resulted in selection of 159 articles for full manuscript review across all three review topics (Functional Outcome, (B) Neuro-physiologic Measures, and Tissue Outcome). One additional reference was added from the reference sections of review papers. A second filter of these 160 references provided 55 that met the final inclusion criteria for the Functional Outcome systematic review, 59 articles for inclusion the Neuro-physiologic Measures systematic review, and four articles for the Tissue Outcome systematic review.

We made substantial efforts to exclude duplicate patient data across studies. However, given that many of the papers came from centers of excellence for TBI research, some of the patient data may be cross reported in multiple studies. This would reduce the total overall number of unique patients. It was impossible, based on the information provided, to tease out all patients reported more than once.

\section{Patient/study demographics}

\section{Functional outcome studies}

Of the 55 articles included in the review $[2,3,6,8-10,12-14$, 16-18, 20, 21, 25, 27-29, 34, 38, 42, 44, 45, 47, 48, 51, 53-55, 60-62, 64-66, 68-71, 73-76, 80, 81, 86, 88, 91-93, $99,103,105,107,108], 33$ were formal manuscript publications and 22 were meeting abstract publications. There were 26 prospective studies, with three randomized control trials (RCT), 22 observational studies, and one single-arm study. Thirteen studies were retrospective series. Finally, 16 studies failed to clarify their study design $[2,3,9,14,27,28,42,45$, $47,60,68,76,86,103,107,108]$. 
All but three studies [29, 42, 103] described populations on non-specified severe TBI patients, with no clear stratification based on primary brain injury pattern on admission neuroimaging. Two studies focused only on patients postdecompressive craniectomy (DC) [29, 103], with no clarification as to the severity/pattern of primary injury. Finally, one study focused only on patients with acute subdural hematomas (aSDH) [42]. Furthermore, details of the intensive care unit (ICU) treatments of these patients were not documented in most studies. Many studies mentioned institutional ICU protocols and ICP/CPP protocols, without giving details of therapies and individual variations in treatment. Furthermore, the application of barbiturate coma, therapeutic hypothermia, and DC were mentioned as potential therapies utilized, leading to significant variation in treatments received by individual patients.

Only three RCTs $[2,20,65]$ and one prospective single arm study [44] provided details of the planned intervention. PostTBI ICU care was mainly left unclear, stating "ICP/CPP directed protocols", leaving room for significant procedural variation between individual patients.

Across all studies there were 2786 patients with severe TBI and assessment between common CMD measures and patient functional outcome. Forty-three patients were post-DC and 19 had aSDH. The remaining 2724 patients were described as severe-TBI patients without a detailed breakdown of injury patterns alongside CMD measures/functional outcomes. Table 1 displays a summary of the patient and study demographics.

\section{Neuro-physiologic measures studies}

Of the 59 articles included in this systematic review [1, 3-5, 7, $10-13,15,17,18,21,25,26,28,34,39,40,44,47,48,51,52$, 56-58, 60-63, 68-72, 74-76, 78, 79, 81-84, 86, 87, 89, 91, 93-101, 105, 109], 30 were prospective observational studies, four were prospective single-arm studies, one was a nonrandomized controlled study, and 12 were retrospective case series. Twelve articles failed to provide enough information in order to determine the exact type of study conducted $[3,15$, $28,47,68,76,79,82,84,86,89,109]$ and were classified as "unknown".

Many studies in this category focused on patients with severe TBI, without significant detail provided regarding the pattern of injuries suffered by individual patients (focal versus diffuse, etc). Furthermore, many studies failed to report CMD measures based on subcategories of severe TBI, only reporting mean values for the entire population studied. Two studies focused only on severe TBI patients whom died, and analyzed CMD measures during the herniation process $[87$, 96], and one study only included severe TBI patients on barbiturate therapy [26]. Descriptions of potential secondary insults and therapies were very limited in the majority of studies.
Where such data were provided, details varied between studies, as did the therapies employed in each study.

Reference to ICP/CPP directed care/therapies was made in many studies, but the description as to how this was achieved was limited or absent. Many studies included significant variations in intensive care unit (ICU)-based therapies, including barbiturates [12, 18, 26] and therapeutic hypothermia [61]. The Lund concept for post-TBI ICU care was applied in some patients [62]. These limitations in data unavailability are unsurprising, since the aims and focus of the different studies was heterogeneous, and in general data were provided to address the specific (often pathophysiological) relationship that was being explored. However, these variations in disease course and physiology, coupled with variations in therapy and incomplete descriptions of the details of therapy made it impossible to undertake comprehensive exploration of the relationships between CMD variables and physiology or therapy.

A total of 2610 patients were studied across all included articles. The mean age varied across all studies, ranging from 8 years to 58.2 years. Twenty-three studies failed to disclose the age of the patients $[3,10,12,15,17,21,28,34,47,58,68$, 72, 74, 76, 83, 84, 86, 89, 91, 93, 94, 96, 109]. Only four studies reported the inclusion of a small number of pediatric patients (age under 16) [51, 56, 61], with only one study clearly displaying the number of pediatric patients [75]. Overall, the total number of pediatric patients is quite small. Some studies included moderate TBI patients with the severe cohorts. It was impossible to separate the two groups. As such, the compiled patient data, both moderate and severe TBI, were included within this review. Study and patient characteristics can be seen in Table 2 .

\section{Tissue outcome studies}

Three of the four articles included in the tissue outcome systematic review $[22,23,53,89]$ were prospective observational studies [22, 23, 89] and one was a retrospective case series [53]. All studies focused on the severe TBI patient population with no specific subcategory of interest declared.

A total of 52 patients were studied. The age of the patients studied was mentioned only in one study [53], where it was reported as a mean of 30.1 years (range, 18-58 years). No specific details of patient comorbidities, acute phase treatment of ICP/CPP, and complications related to critical illness were report in any of the studies included in the review. Study and patient demographics can be seen in Table 3 .

\section{CMD measurement technique}

Details of the use of CMD monitoring were present in many studies. The most commonly quoted sampling intervals ranged from $30 \mathrm{~min}$ to hourly. Unfortunately, the use of 


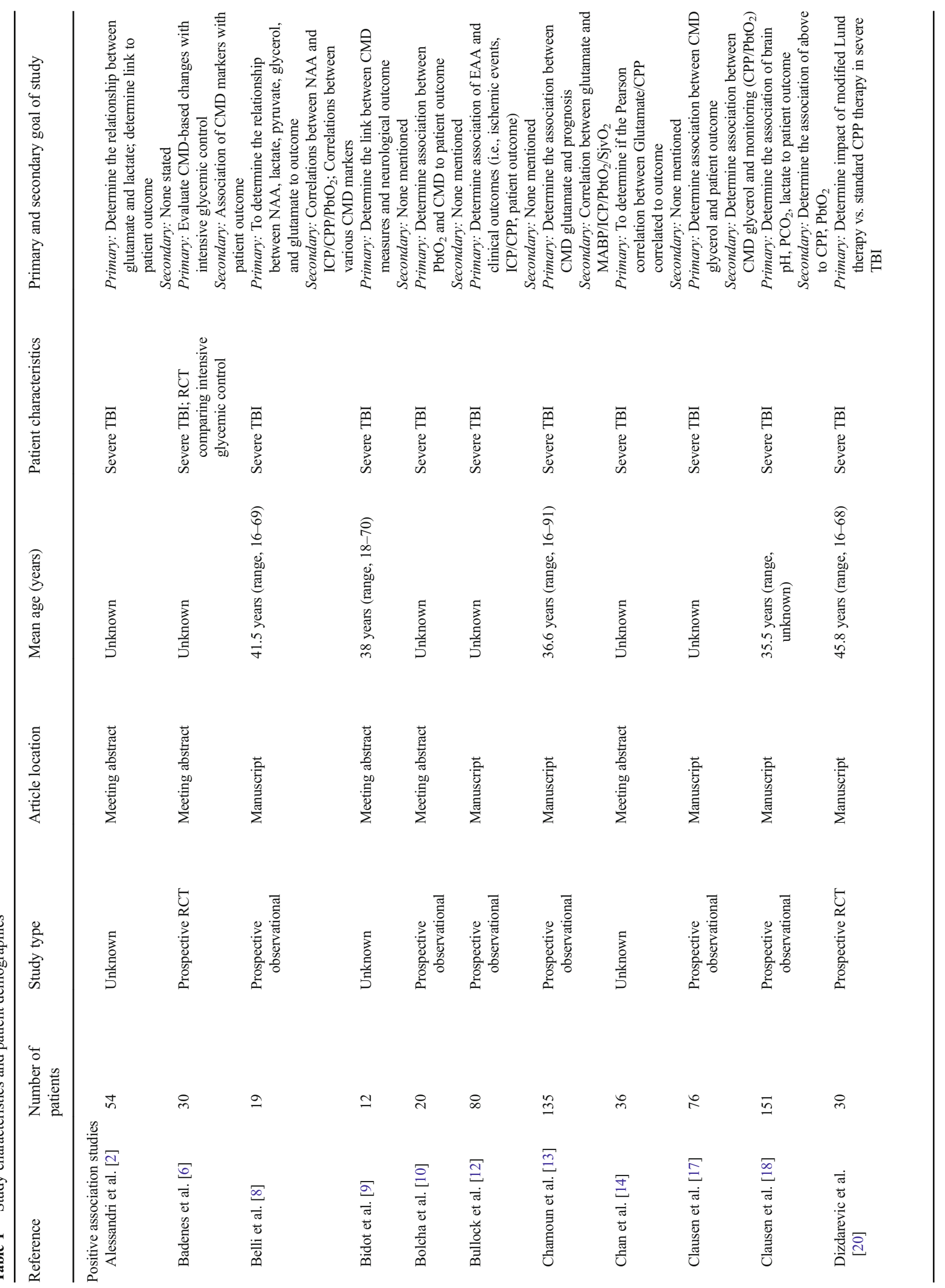




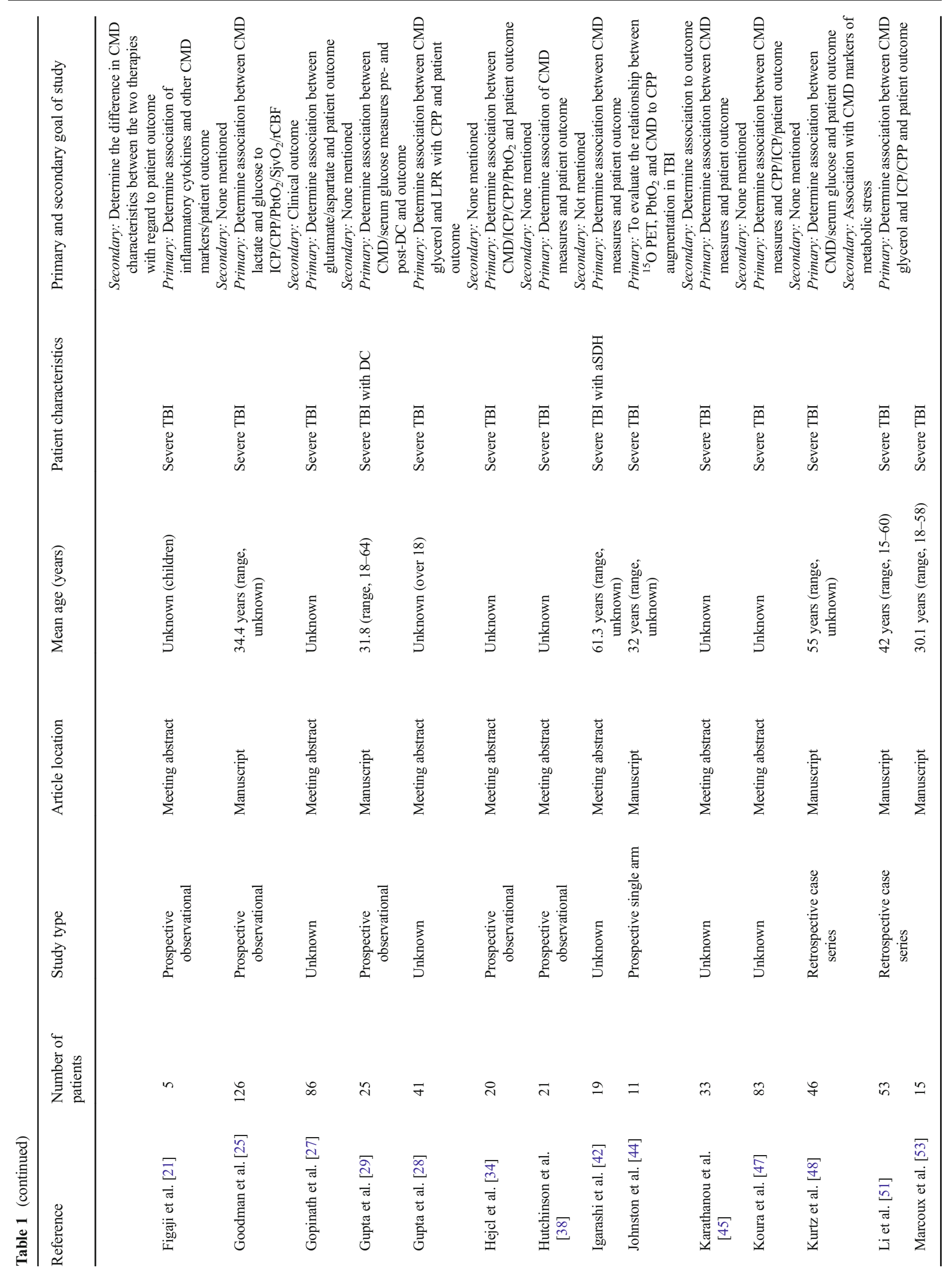




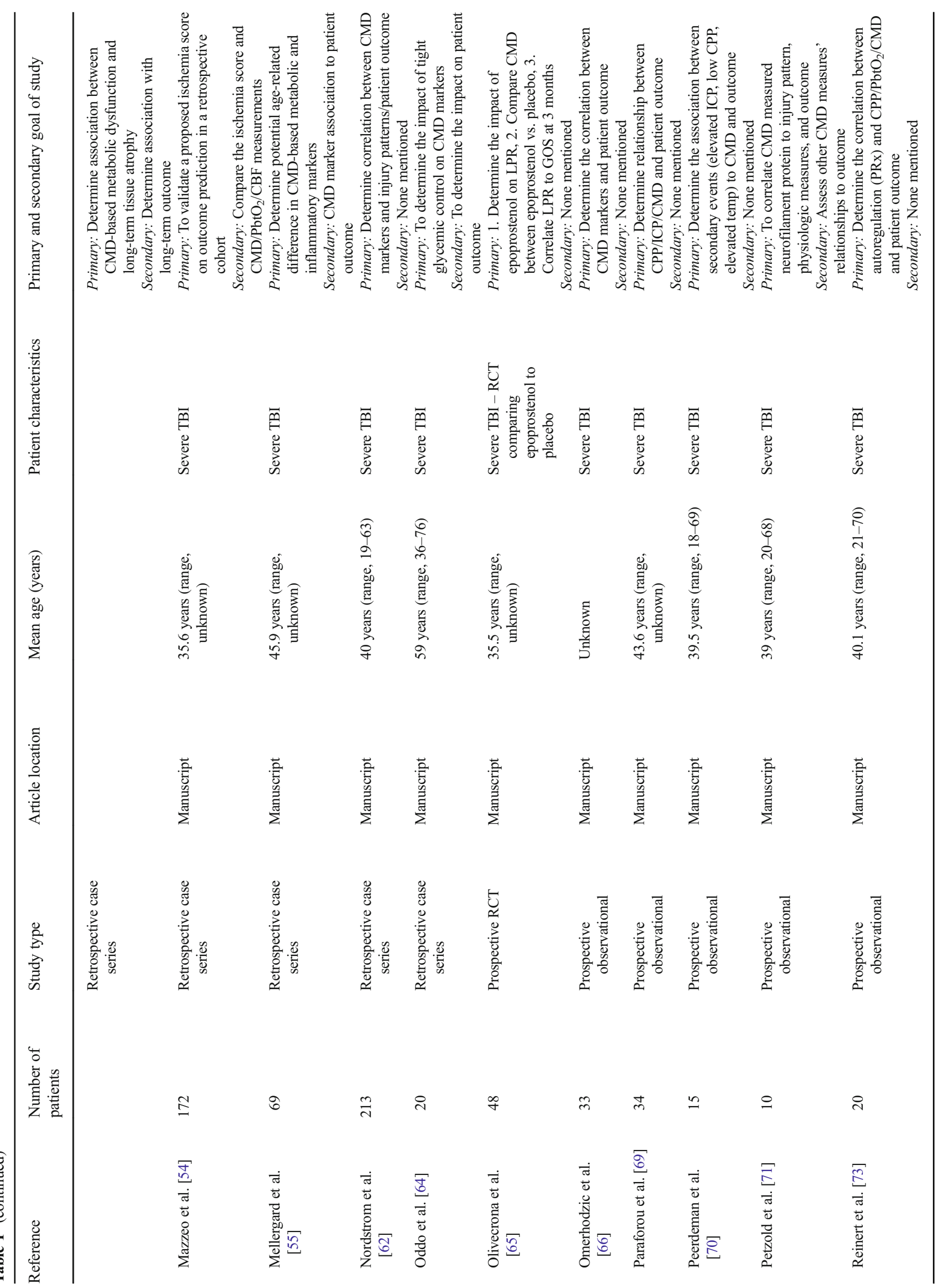




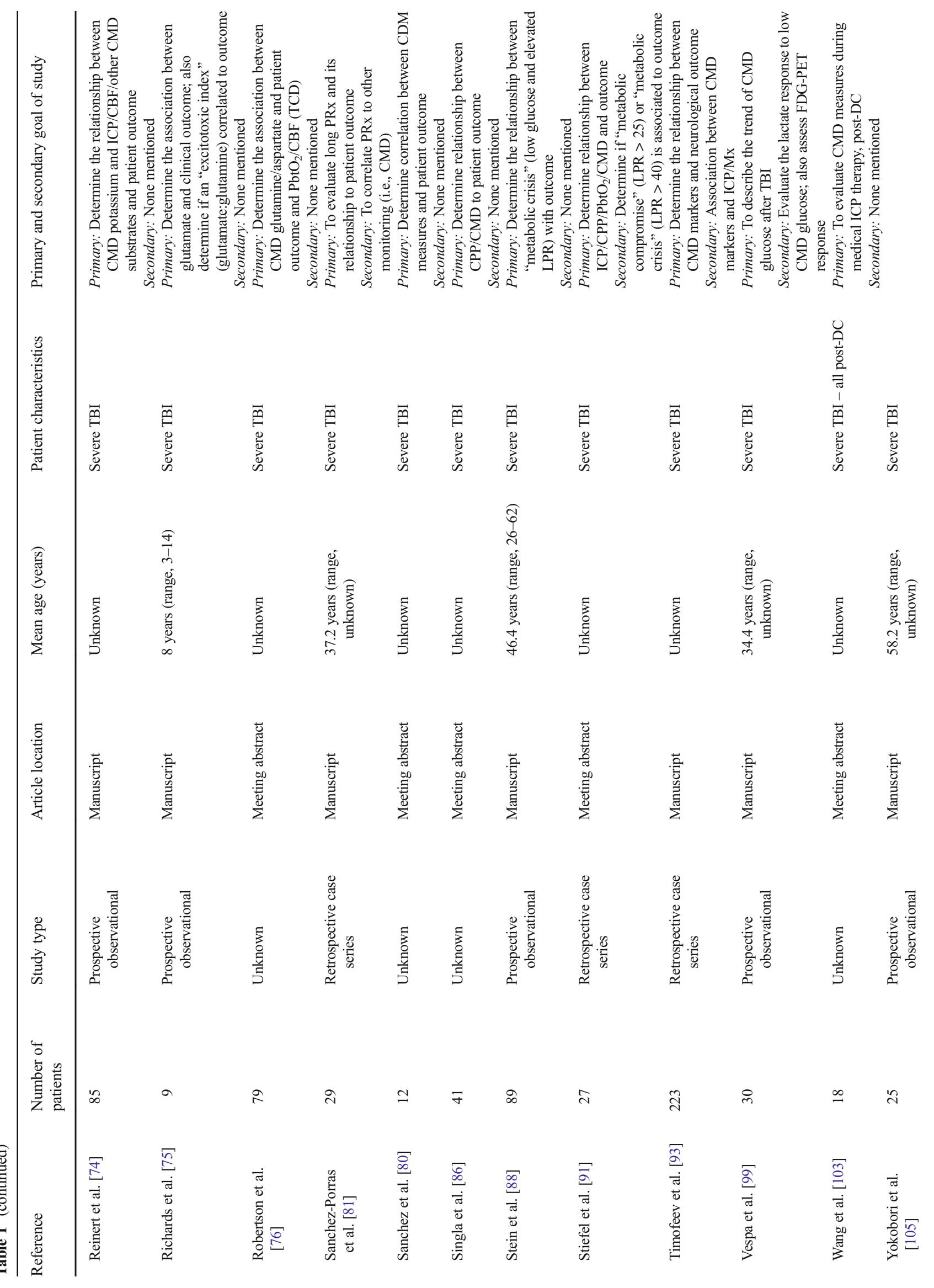




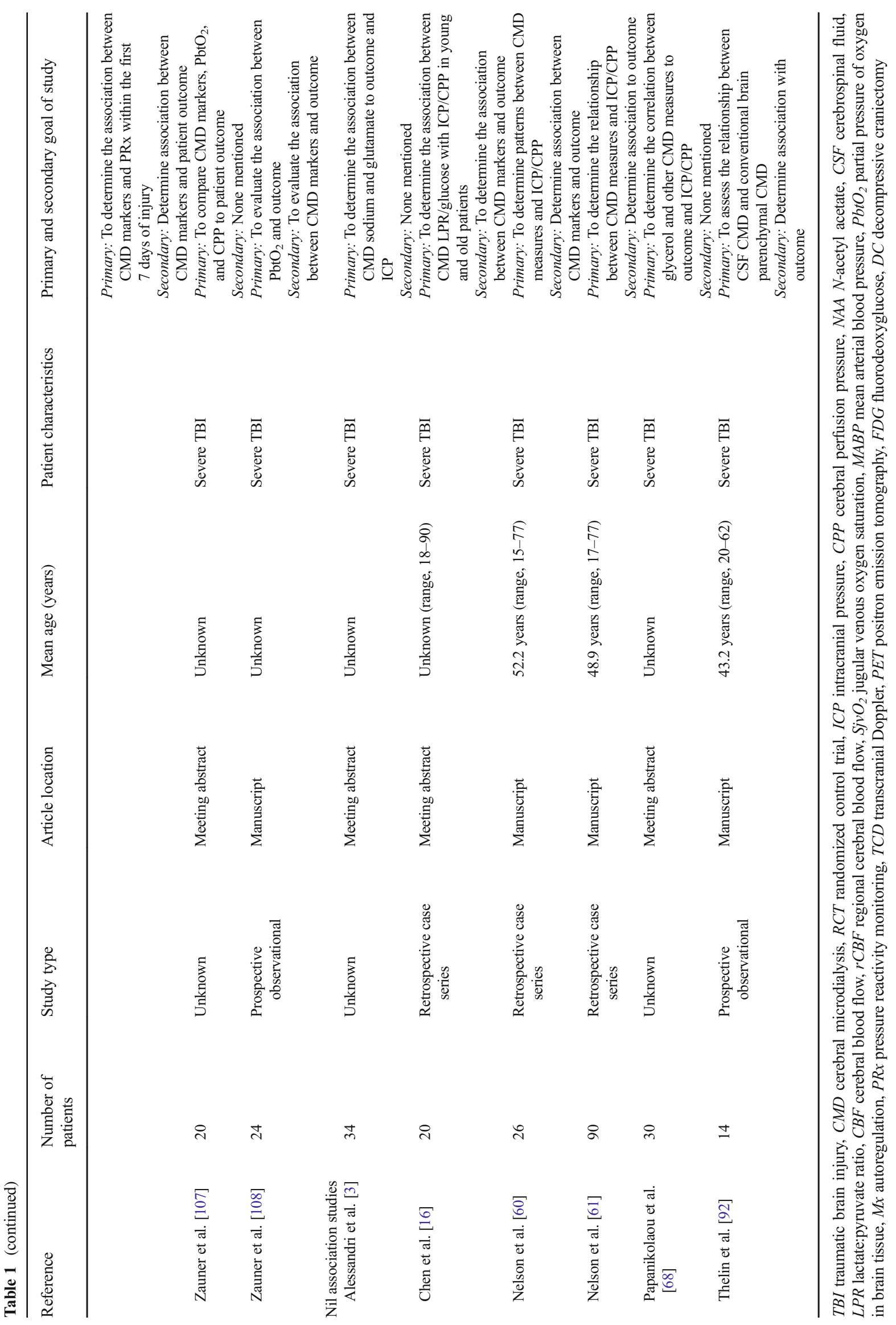




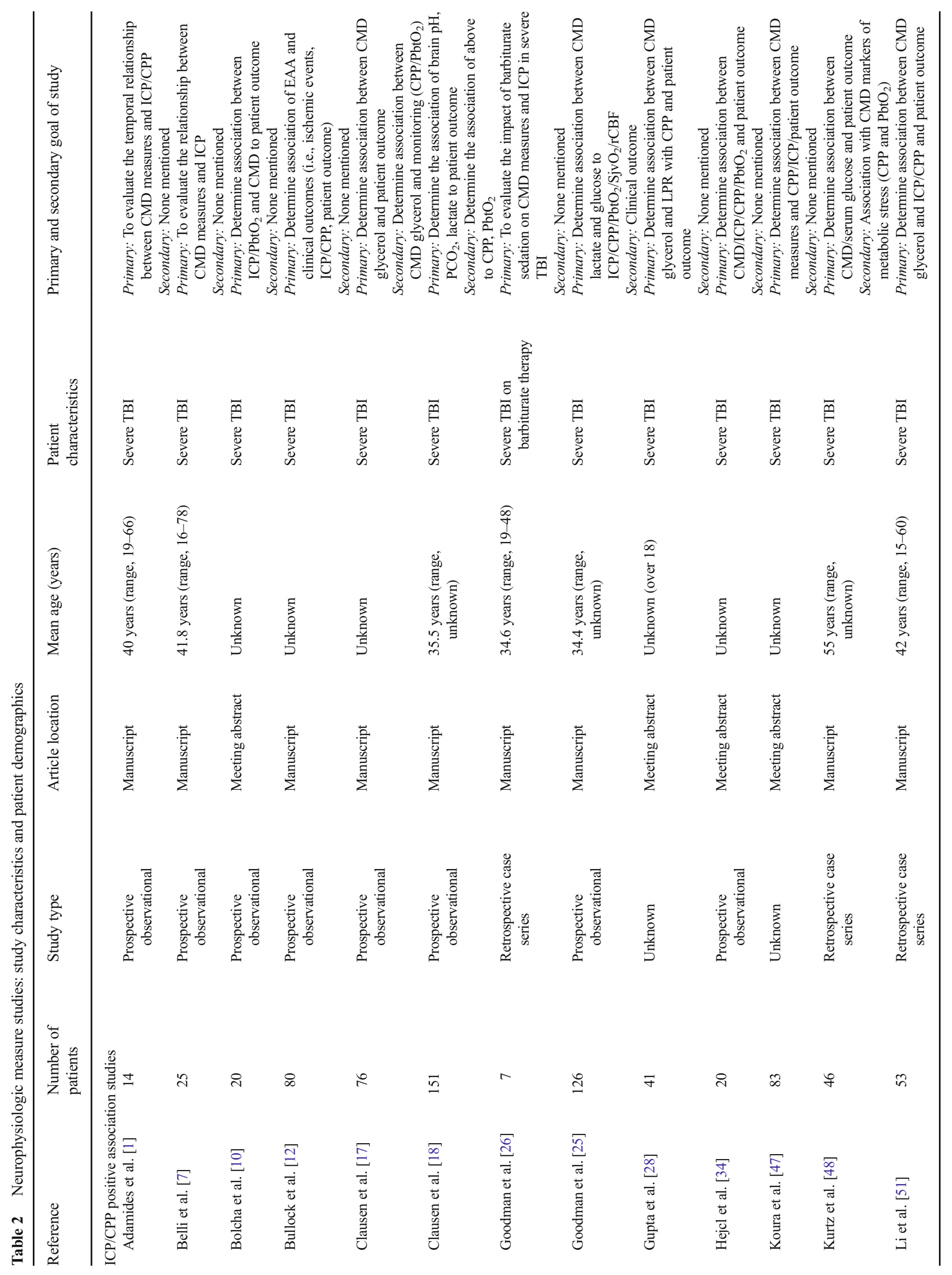




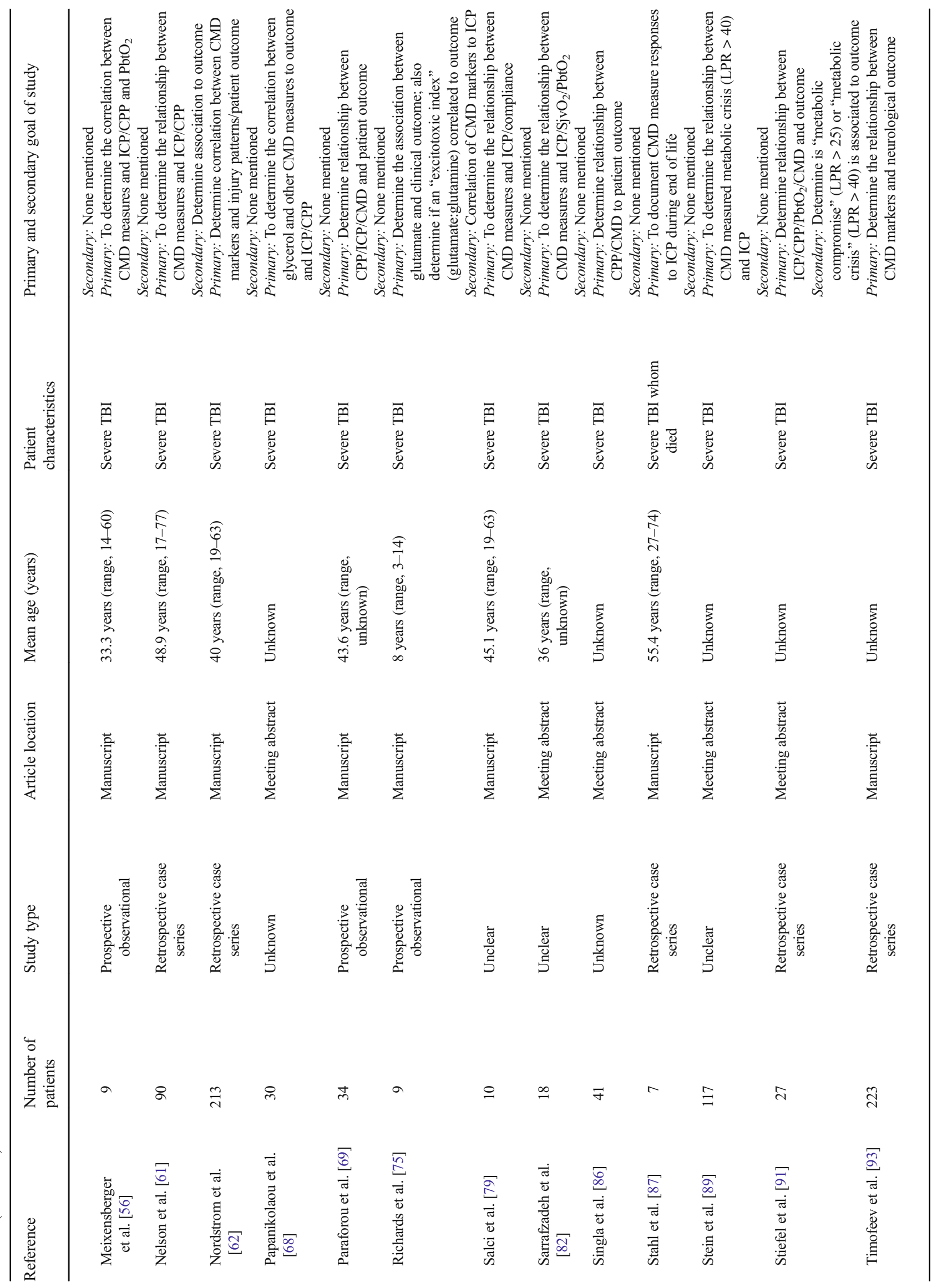




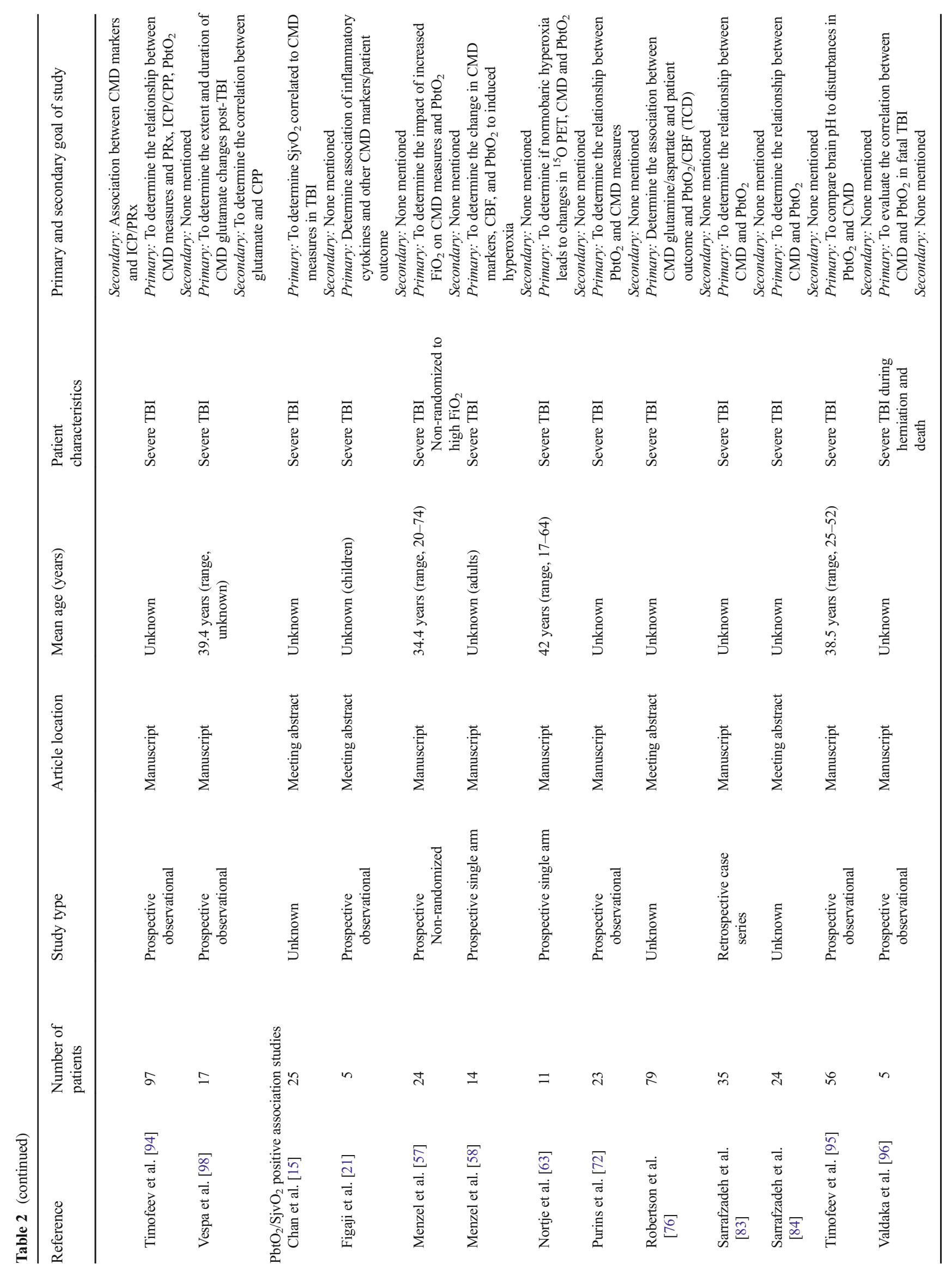




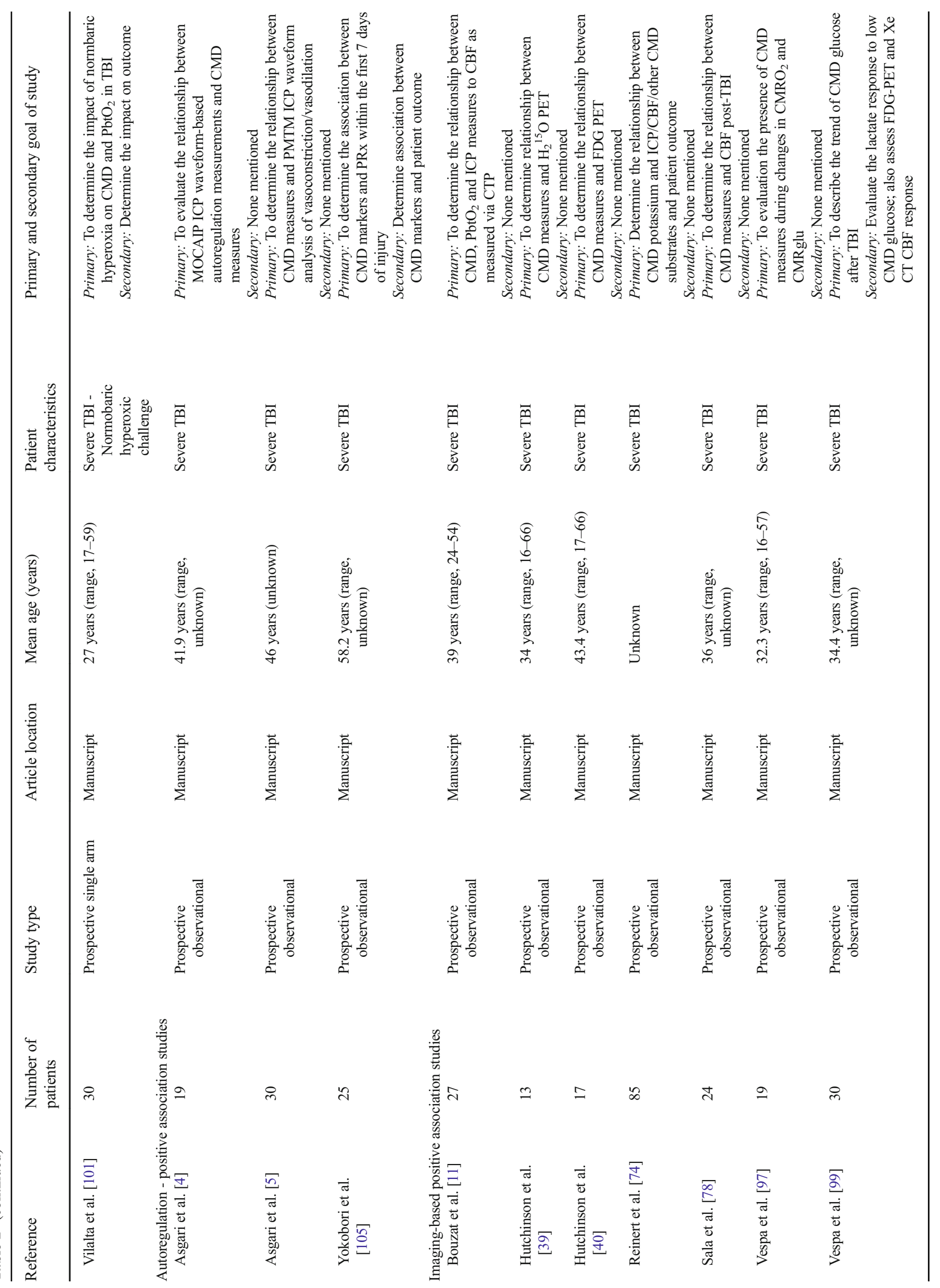




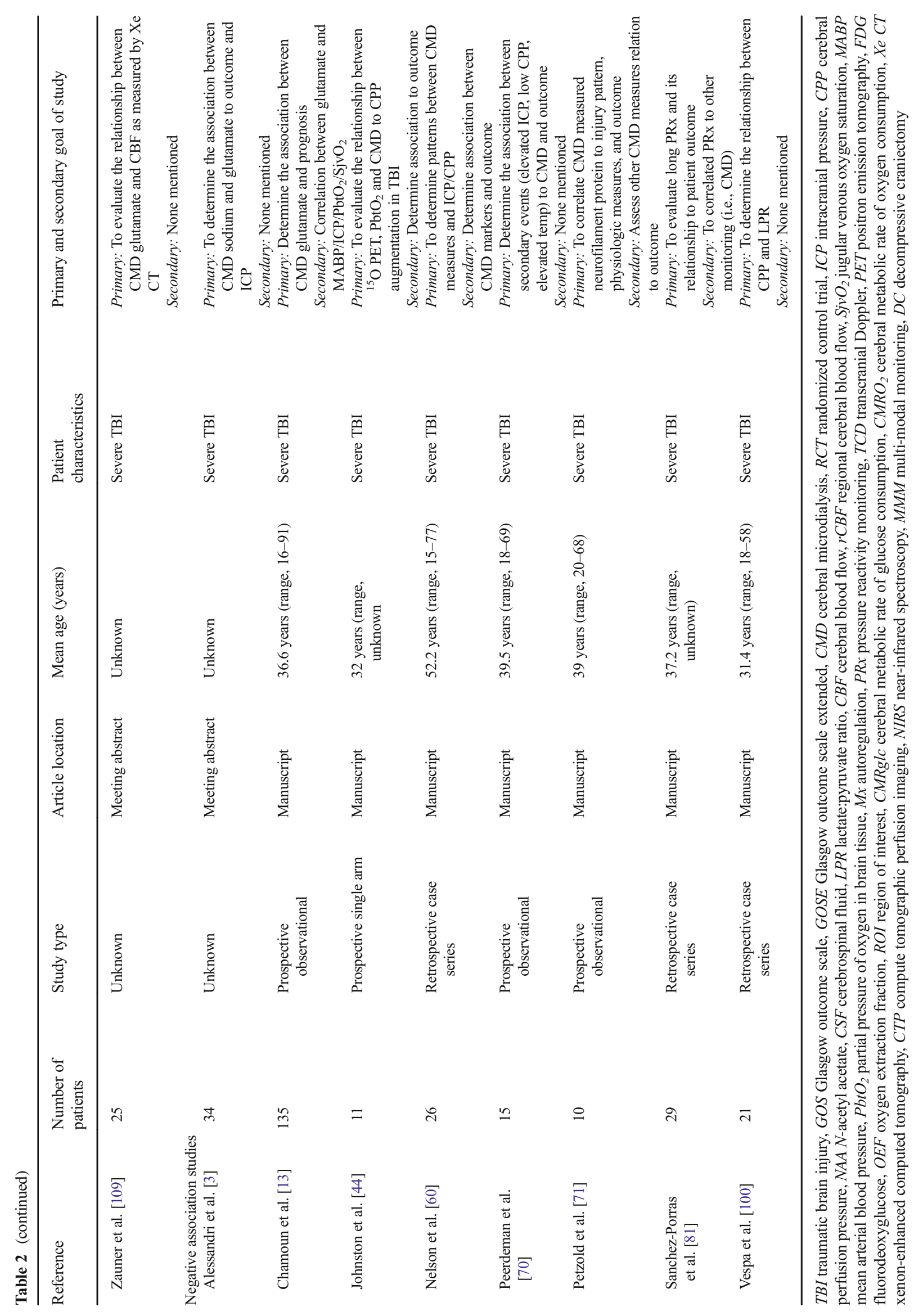


pooled sample analysis was not always clear. Consequently, despite hourly sampling, the data in most manuscripts did not allow us to exclude the possibility that samples may have been pooled over longer periods and analyzed for substrates over these integrated time intervals.

The most commonly reported CMD measures included: glucose, lactate, pyruvate, LPR, \pm glutamate. Some studies reported CMD measure of only one substrate, typically glutamate or lactate.

A summary of the CMD measurement techniques for the functional outcome, neuro-physiologic measure, and tissue outcome studies can be seen in Appendix C of the Supplementary materials. Furthermore, a study-by-study tabulation of CMD measurement details can be seen in Appendices E, F, and G of the Supplementary materials.

\section{Measures of outcome}

A summary of the various techniques employed in the measurement of functional outcome, neuro-physiologic measures and tissue outcome can be seen within Appendix D of the supplementary materials. Furthermore, a study-by-study tabulation of the outcome measure documented can be seen in Appendices E, F, and G of the Supplementary materials.

\section{Patient functional outcome - positive association studies}

\section{Glucose}

Thirteen studies documented an association between CMD measured glucose and mortality/Glasgow Outcome Scale (GOS) at 3-6 months [6, 9, 29, 38, 48, 54, 64, 66, 73, 80, $105,107,108]$. The documented association was that low CMD glucose was associated with patient functional outcome. The mean value for "low" CMD glucose varied across studies (range, 0.46-1.39 mmol/l), with these values being significantly lower than the "good" outcome cohorts. Of note, one study quoted a mean value of $13.8 \mathrm{mmol} / \mathrm{l}$ in the poor outcome group within a table, however we suspect this was a typo in units (i.e., $\mathrm{mmol} / \mathrm{l}$ instead of $\mathrm{mg} / \mathrm{l}$ ).

One study reported an association between high lactate:glucose ratio (LGR) to outcome [54]. In addition, one study reported an association between low brain:serum glucose levels $(<0.12)$ and poor patient outcome [48].

\section{Glutamate}

Fourteen studies documented an association between CMDmeasured glutamate levels and patient outcome as assessed by mortality and GOS at 3-6 months $[2,12-14,27,38,47,55$, $75,76,81,86,93,105]$. A threshold of glutamate greater than $20 \mu \mathrm{mol} / \mathrm{l}$ was reported in many of these studies to be associated with mortality and poor GOS at 3-6 months post-injury. 


\section{Glycerol}

Fourteen studies reported an association between CMD measured glycerol and patient outcome, measured as mortality and/or GOS at 3-6 months $[8,10,17,20,28,34,42,45,51$, $54,69,70,93,105]$. There was a documented statistically significant association between elevated mean CMD glycerol levels and increased mortality/poor outcome at 3-6 months $[12-14,27]$. The reported ranges for "high" CMD glycerol varied substantially across studies, with the "poor" outcome cohorts displaying mean levels ranging from $83 \mu \mathrm{mol} / 1$ to over $150 \mu \mathrm{mol} / \mathrm{l}$.

\section{Lactate/LPR}

Twenty-five studies reported an association between CMDmeasured LPR and patient functional outcome, as assessed by mortality and GOS at 3-6 months [8-10, 20, 21, 28, 34, $38,42,44,45,53,55,62,65,69,71,80,86,88,92,93,99$, 103, 105]. All studies documented a significant association between elevated mean LPR (or baseline admission LPR) and increased mortality/poor GOS at 3-6 months. The threshold values reported for poor outcome varied significantly, ranging from 25 up to and exceeding 80 . The most commonly quoted LPR thresholds for poor outcome ranged between 25 and 40.

Fourteen studies reported separate associations between the mean CMD lactate concentration and increased mortality and/ or poor outcome at 3-6 months $[2,9,18,25,38,42,54,73$, $80,81,93,99,107,108]$. Only one study made direct comments about pyruvate levels and associated mortality/morbidity. This study reported that sustained mean pyruvate levels below $70 \mu \mathrm{mol} / 1$, with LPR $>30$, are associated with mortality at 6 months [62].

\section{Potassium}

Only one study was found describing the association between CMD potassium and patient outcome, as assessed via a dichotomized GOS at 3 months [74]. This study documented an association between mean potassium levels less than $1.8 \mathrm{mmol} / \mathrm{l}$ and good outcome at 3 months $(p<0.0001)$. The measurement of potassium levels in recovered microdialysate can be challenging as the perfusion fluid often contains potassium.

\section{Neuro-physiologic measures - positive association studies}

\section{$C M D$ association with $I C P / C P P$}

Overall, there were 1684 patients described within studies which found positive association between one or more common CMD measures and ICP and/or CPP.
The mean LPR was found to be associated with ICP/CPP in 15 studies [1, 7, 10, 28, 34, 61, 62, 69, 79, 86, 87, 89, 93]. Seven studies displayed an association between elevated ICP and an increase in LPR [7, 10, 69, 79, 87, 89, 93]. Four studies displayed an association between low CPP and elevated LPR $[28,62,86,91]$. Finally, four studies described an association between elevated ICP/low CPP and increased LPR [1, 34, 61, 94]. Various LPR thresholds were described for these relationships, with and LPR of greater than 25 to 40 being the most commonly quoted.

Elevated mean glutamate was found to be associated with ICP/CPP in 11 studies [1, 7, 12, 26, 47, 56, 75, 82, 87, 93, 98]. Elevated mean glutamate was seen during episodes of increased ICP in eight studies [7, 26, 47, 56, 75, 82, 87, 91], and increased ICP/low CPP in three studies $[1,12,98]$. Glutamate thresholds for this association were seldom reported, with only one study reporting levels greater than $20 \mu \mathrm{mol} / 1$ as statistically associated with ICP/CPP [12].

Elevated mean glycerol was found to be associated with ICP/CPP in 12 studies [1, 7, 10, 17, 34, 48, 61, 68, 69, 86-88]. Increased mean glycerol was seen during episodes of increased ICP in seven studies [7, 10, 34, 68, 69, 87, 89], low CPP in two studies [17, 86], and elevated ICP/low CPP in three studies [1, 51, 61]. Like glutamate, glycerol thresholds seen during these associations were not commonly described, with only one study reporting a threshold of $100 \mu \mathrm{mol} / 1$ [7].

Some studies described relationships between common CMD markers and ICP/CPP that were less robust. Mean CMD lactate elevations, in isolation, were found to be associated with elevated ICP and/or low CPP in only four studies $[18,25,61,78]$. Low mean glucose was associated with elevated ICP and/or low CPP in three studies [25, 48, 56]. Finally, high potassium levels were associated with ICP elevations in one study [74].

\section{CMD association with $\mathrm{SjvO}_{2}$}

Three studies referred to some association between common CMD measures and $\mathrm{SjvO}_{2}$, totaling 169 patients [15, 25, 82]. Elevated mean lactate was found to be associated with low $\mathrm{SjvO}_{2}$ in three studies [15, 25, 82]. Increased mean glutamate and glycerol were also found to be associated with low $\mathrm{SjvO}_{2}$ in two studies [15, 82].

\section{CMD association with $\mathrm{PbtO}_{2}$}

Eighteen studies made some reference to a positive association between one or more common CMD measures and $\mathrm{PbtO}_{2}$, totaling 746 patients $[10,17,18,21,34,47,56,58$, $63,72,76,82-84,94-96,101]$. Location of the $\mathrm{PbtO}_{2}$ probe is believed to have been near the CMD probe in all studies, though this was not explicitly stated in the majority. Low $\mathrm{PbtO}_{2}$ was found to be associated with elevated mean LPR 
in 11 studies [10, 15, 34, 48, 56, 63, 72, 94-96, 101], elevated mean glycerol in three studies [17, 72, 82], elevated mean glutamate in five studies [72, 76, 82, 83, 96], elevated mean lactate alone in seven studies $[18,21,58,82,95,96,101]$, low mean glucose in three studies $[48,85,101]$, and high mean potassium in one study [96].

\section{CMD association to autoregulation}

An association between autoregulation measures and common CMD measures was reported in five studies, totaling 394 patients $[4,5,93,94,105]$. Pressure reactivity index (PRx) monitoring was utilized in three studies, with an association between worsening autoregulation and elevated mean LPR [93, 94, 105], glutamate [93], glycerol [93], and glucose [105]. Two studies reported autoregulation measurement via ICP computational waveform analysis, with an association between poor autoregulation and elevated LPR $[4,5]$.

\section{CMD associations with cerebral blood flow and metabolism}

Ten studies reported an association between CMD analytes and measures of cerebral blood flow using a variety of techniques (PET, CTP, Xe CT, TCD (transcranial Doppler) or laser Doppler flowmeter), totaling 372 patients $[11,39,40,51,74$, 76, 78, 99, 109].

Two studies reported a correlation between LPR and ${ }^{15} \mathrm{O}$ PET measurements, with the following relationships described: positive correlation between LPR and oxygen extraction fraction (OEF) [39], and a negative correlation between LPR and cerebral metabolic rate of oxygen consumption $\left(\mathrm{CRMO}_{2}\right)$ [97]. The ROI for these PET studies was near the CMD catheter. A CTP-based assessment of $\mathrm{CBF}$ was described in five studies. Two studies described CTP based decreases in CBF in association with low glucose/elevated LPR [11] and glycolytic lactate elevations [78]. Three studies utilized Xe CT, detailing an association between elevated mean potassium [74], elevated mean glutamate [108], and decreased mean glucose [99] with reduced CBF. Transcranial Doppler ultrasonography was applied in two studies. One described TCD based decrease in CBF velocities associated with elevated mean glutamate. The second study detailed laser Doppler flowmeter assessment of CBF, with an association between elevated glycerol and low CBF identified.

Two studies reported an association between fluorodeoxyglucose (FDG) PET and common CMD measures, with the following relationships: increased lactate/ pyruvate positively correlated to cerebral metabolic rate of glucose consumption $\left(\mathrm{CRM}_{\mathrm{GLC}}\right)$ [40], and low glucose correlated to increased FDG uptake [99].

\section{Tissue outcome - positive association studies}

Two studies included within the review were identified as "positive" studies, in that an association between CMD measures and tissue fate were identified. Details can be seen in Table 3.

One of these studies was a meeting abstract describing the use of MRS and MR diffusion tensor imaging (DTI) at an undisclosed interval in the acute/subacute phase post-injury [23]. The MRS analysis focused on $N$-acetyl aspartate (NAA), choline (Cho), and creatinine $(\mathrm{Cr})$ peaks, in addition to apparent diffusion coefficient (ADC) on MRI imaging. The goal was to identify possible areas of ischemia/infarction using ADC thresholds and identify areas of neuronal loss on MRS measures. The region of interest (ROI) for the MRS voxel target was around the area of the CMD probe, which was in an unspecified location (with radiologically normal (no structural injury on CT) versus lesional tissue). The location of the "control" voxel was unclear in these patients. The study demonstrated a negative correlation between CMD LPR and MRS defined NAA $(p=0.037)$ and Cr peaks $(p<0.001)$. In addition, CMD measured glucose was positively correlated with the Cho peak $(p=0.007)$ and NAA/Cho ratio $(p=0.028)$.

The second "positive" study focused on long-term assessment of chronic frontal lobe atrophy at 6 months post-injury [53]. This article utilized an MRI volumetric based assessment of frontal lobe atrophy and attempted to determine an association with acute/subacute CMD measures from "healthy tissue". It was found that the degree of LPR elevation and the duration of abnormal LPR were positively associated with frontal lobe atrophy at 6 months $(p<0.01)$. In addition, it was noted that the percentage of time spend with LPR values greater than 40 directly correlated to frontal lobe atrophy at 6 months.

\section{Nil association studies}

Overall, for the majority of the studies identified documented positive associations between one or more CMD analyte and the various outcomes of interest. A minority of studies, and thus the minority of the overall patient population documented within the literature, reported a "nil" association between a specific CMD analyte and outcome (i.e., functional, neurophysiologic, or tissue). A summary of the "nil" association studies can be found within Appendix $\mathrm{H}$ of the Supplementary materials. Furthermore, a study-by-study breakdown of the "nil" association studies can be found in Appendices E, F, and G of the Supplementary materials.

\section{Complications of CMD monitoring}

\section{Functional outcome studies}

Many studies failed to document complications/harms associated with CMD monitoring. Only four studies mentioned 
documentation of complications [8, 12, 65, 99]. Two studies stated "no complications" $[65,99]$. One study documented a focal intra-cerebral hemorrhage (ICH) during insertion which required surgical evacuation [4]. Finally, one study described three instances of CMD catheter malfunction, requiring reinsertion of a new catheter [12].

\section{Neuro-physiologic measure studies}

Only five studies reported complications related to CMD monitoring [7, 12, 56, 98, 99]. Three studies reported "no complications" related to CMD [7, 98, 99]. Two studies reported CMD catheter malfunction in a total of five patients $[12,56]$.

\section{Tissue outcome studies}

All studies identified failed to disclose any complications related to CMD monitoring.

\section{Assessment of bias}

The risk of bias was assessed via the RTI item bank [102], with the results tabulated in Appendix B of the supplementary material. Overall, all meeting abstracts included within these systematic reviews were deemed very high risk in almost all categories in the RTI bank. A short descriptive reasoning for the bias assessments can also be found in Appendix B.

\section{Level of evidence}

\section{Functional outcome}

As previously outlined, the level of evidence was assessed as per GRADE criteria through consensus amongst the authors. Given the overall high bias risk and shortcomings of all the studies included within the systematic review, the level of evidence ranges from low to very low in support of an association between common CMD measures and patient outcome as assessed by mortality and GOS at 3-6 months. A summary can be seen in Table 4 .

\section{Neuro-physiologic measures}

Overall level of evidence for the common CMD measures and their relationship to physiologic measures were assessed via the GRADE criteria. This assessment showed that most CMD biomarkers displayed very low evidence in support of a relationship with specific physiologic measures. Given the limitations listed above, we were limited in the strength of conclusions that we provide.

There currently exists GRADE C level of evidence supporting an association between CMD measured LPR, glutamate and glycerol with ICP and/or CPP. In addition, there currently exists GRADE $\mathrm{C}$ evidence to support an association between LPR and $\mathrm{PbtO}_{2}$. All remaining CMD measures displayed either GRADE D evidence, or occasionally no evidence, to support a relationship with physiologic measures. A tabulated summary of the GRADE evidence can be seen in Table 5 .

Table 4 GRADE level of evidence for CMD measures and patient functional outcome

\begin{tabular}{|c|c|c|}
\hline CMD measure & Association with patient functional outcome & GRADE level of evidence \\
\hline Glucose & $\begin{array}{l}\text { Low mean glucose is associated with poor } \\
\text { outcome/mortality at 3-6 months post-injury }\end{array}$ & $\begin{array}{l}\mathrm{C} \text { (Low) - Large number of studies } \\
\text { with significant limitations }\end{array}$ \\
\hline Glutamate & $\begin{array}{l}\text { High mean glutamate is associated with poor } \\
\text { outcome/mortality at 3-6 months post-injury }\end{array}$ & $\begin{array}{l}\text { C (Low) - Large number of studies } \\
\text { with significant limitations }\end{array}$ \\
\hline Glycerol & $\begin{array}{l}\text { High mean glycerol is associated with poor } \\
\text { outcome/mortality at 3-6 months post-injury }\end{array}$ & $\begin{array}{l}\text { C (Low) - Large number of studies } \\
\text { with significant limitations }\end{array}$ \\
\hline LPR & $\begin{array}{l}\text { Elevated mean LPR ( }>25 \text { to } 40 \text { ) is associated with } \\
\text { poor outcome/mortality at 3-6 months post-injury }\end{array}$ & $\begin{array}{l}\text { C (Low) - Large number of studies } \\
\text { with significant limitations }\end{array}$ \\
\hline Lactate & $\begin{array}{l}\text { Elevated mean lactate is associated with poor } \\
\text { outcome/mortality at 3-6 months post-injury }\end{array}$ & $\begin{array}{l}\text { C (Low) - Large number of studies } \\
\text { with significant limitations }\end{array}$ \\
\hline Pyruvate & $\begin{array}{l}\text { Persistently low mean pyruvate levels, in the presence } \\
\text { of elevated LPR, is associated with üoor outcome }\end{array}$ & $\begin{array}{l}\text { D (Very Low) - limited number of studies } \\
\text { evaluating pyruvate in isolation; significant } \\
\text { limitations identified within these studies }\end{array}$ \\
\hline Potassium & $\begin{array}{l}\text { Mean potassium levels less than } 1.8 \mathrm{mmol} / \mathrm{l} \text { is associated } \\
\text { with a good GOS at } 3 \text { months post-injury }\end{array}$ & D (Very Low) - one study with limitations \\
\hline Sodium & $\begin{array}{l}\text { There is no association between mean CMD sodium } \\
\text { levels and outcome }\end{array}$ & D (Very Low) - one study with limitations \\
\hline
\end{tabular}

$C M D$ cerebral microdialysis, $L P R$ lactate:pyruvate ratio, mmol millimolar, $l$ liter, GOS Glasgow Outcome Scale 


\section{Tissue outcome}

Given the significant limitations in each study based on design and bias risk assessment, it was difficult to assign a formal GRADE level of evidence. Furthermore, there were studies both in support and against any correlation between CMD measures and tissue outcome. Thus, we are left with the following conclusions.

There exists GRADE D (very low) evidence to suggest an association between CMD measured LPR greater than 40 in the acute/subacute phase and frontal lobe atrophy at 6 months post-injury.

There is unclear evidence to suggest a correlation between CMD measures and MRS or ADC-based tissue outcome assessment, with both low-quality evidence to support and refute an association at this time.

\section{Discussion}

We believe that this three-stage systematic review includes the major available studies documenting the relationship between common CMD analytes and Patient Functional Outcome (55 studies), Neurophysiologic Measures (59 studies), and Tissue Outcome (four studies). In broad terms, this systematic review replicates the pragmatic summary of literature that underpinned the previous consensus statements on CMD [41, 49, 50]. Our analysis strengthens the evidence for many of these associations by identifying a significantly larger number of studies than were cited in recent consensus statements $[49,50]$.
Further, we document the level of evidence based on conventional evaluation frameworks for evidence based medicine. This assessment found the following evidence:

1. Patient Functional Outcome - GRADE level C evidence to support an association between CMD measured glucose, glutamate, glycerol, lactate, LPR and patient functional outcome as assessed by mortality and GOS at 36 months post-injury. These CMD measures have over ten studies in support of this relationship, with the majority documenting overwhelming statistical significance. Furthermore, there exists GRADE D level of evidence identified to support a relationship (positive or "nil") between CMD measured pyruvate, potassium, sodium, and patient outcome. These CMD measures had much less robust literature to support an association with outcome.

2. Neurophysiologic Measures - GRADE C evidence for a relationship between elevated LPR and elevated ICP and/ or low CPP. We also judged that there was GRADE C evidence supporting an association between elevated glutamate and glycerol with elevated ICP and/or low CPP, and between elevated mean LPR and low $\mathrm{PbtO}_{2}$. All remaining CMD measures displayed either GRADE D evidence, or occasionally no evidence, to support a relationship with physiologic measures.

3. Tissue Outcome - GRADE D of evidence to suggest an association between LPR in the acute/subacute phase of illness and frontal lobe atrophy at 6 months. The available literature reports no consistent association between CMD measures and MRS or ADC can be made at this time, other than the literature is "unclear".

Table 5 GRADE level of evidence for association between CMD analytes and physiologic measures

\begin{tabular}{|c|c|c|c|}
\hline Physiologic measure & GRADE level of evidence & CMD measure(s) & Rationale \\
\hline \multirow[t]{2}{*}{$\mathrm{ICP} / \mathrm{CPP}$} & C (low) & LPR, glutamate, glycerol & $\begin{array}{l}\text { Several studies with large patient numbers } \\
\text { and statistically significant relations but } \\
\text { major study limitations in all }\end{array}$ \\
\hline & $\mathrm{D}$ (very low) & $\begin{array}{l}\text { Lactate (alone), pyruvate (alone), } \\
\text { glucose, potassium }\end{array}$ & Small number of studies with severe limitations \\
\hline $\mathrm{SjvO}_{2}$ & $\mathrm{D}$ (very low) & Lactate (alone), glutamate, glycerol & $\begin{array}{l}\text { Very limited number of studies with } \\
\text { significant bias/limitation }\end{array}$ \\
\hline \multirow[t]{2}{*}{$\mathrm{PbtO}_{2}$} & $\mathrm{C}$ (low) & LPR & Several studies with severe limitations \\
\hline & $\mathrm{D}$ (very low) & $\begin{array}{l}\text { Glycerol, glutamate, lactate, } \mathrm{p} \\
\text { otassium glucose }\end{array}$ & $\begin{array}{l}\text { Very limited number of studies. All significantly } \\
\text { flawed. Publication bias high in this area. }\end{array}$ \\
\hline $\begin{array}{l}\text { Autoregulation } \\
\text { (PRx and ICP } \\
\text { waveform analysis) }\end{array}$ & $\mathrm{D}$ (very low) & LPR, glutamate, glycerol & $\begin{array}{l}\text { Very limited number of studies. Bias high. } \\
\text { Publication bias very high. }\end{array}$ \\
\hline Imaging & No GRADE applied & N/A & $\begin{array}{l}\text { This area of the literature was extremely scarce, } \\
\text { heterogeneous, suffering from publication bias, } \\
\text { design bias. Thus, we felt it inappropriate to assign } \\
\text { any GRADE level to this area at this time }\end{array}$ \\
\hline
\end{tabular}

$I C P$ intracranial pressure, $C P P$ cerebral perfusion pressure, $\mathrm{CMD}$ cerebral microdialysis, $\mathrm{Sjv}_{2}$ jugular venous oxygen saturation monitoring, $\mathrm{PbtO}_{2}$ brain tissue oxygen level monitoring, $P R x$ pressure reactivity index monitoring, $L P R$ lactate:pyruvate ratio 
However, we had also hoped that integration of the results from these studies would allow us to draw more robust conclusions regarding the relationship of CMD variables and clinical outcome or physiological metrics, with the large summed sample size allowing greater methodological rigor and increased statistical power. However, when compared to large individual studies in the systematic review, the integration of patients from all of the relevant studies did not provide more robust statistical foundations for a specific CPP or ICP threshold. Finally, we found a paucity of data in the area of tissue outcome studies, which was surprising given that follow-up imaging in this population should be common place, and retrospective analysis of CMD measures and imaging based tissue outcome should be possible. We were also surprised that for the tissue outcome studies, the exclusive focus of the CMD measures was lactate, pyruvate and LPR (i.e., markers of metabolic "crisis"). Glutamate and other excitatory amino acids, and markers of tissue distress (glycerol) were not included in most studies on tissue outcome assessment. Inclusion of these markers may display a correlation to acute/subacute and chronic tissue changes.

\section{Limitations}

Despite the interesting results generated by the systematic review, we were unable to grade this evidence as being of a high quality based on RTI criteria, because of the omission of information which might have allowed us to grade the studies at a higher level of evidence. The reasons for this discordance are worth exploring, since its drivers will allow us to help design data collection in a future generation of studies.

One critical set of limitations in most studies was the absence of clear statements that documented the absence of bias in reporting, and hence resulted in categorizing these studies as being at high risk of bias based on the criteria in the RTI item bank [102]. There was some heterogeneity in reporting and some studies may not suffered from the relevant biases, but we were unable to exclude these based on the information provided. One key issue is the basis for selection of the patients included in analysis in individual studies, since this impacts substantially on the generalizability of the conclusions we draw, and the population of patients in whom the results of the study might apply.

A second key issue was the absence of documented blinding of outcome assessors to the CMD results. While the outcome assessors may not have been biased by knowledge of the CMD results, the absence of clear documentation of such blinding results in a downgrading of the quality of evidence in studies based on RTI criteria. In addition, reported thresholds for individual CMD measures and their association with outcome were substantially varied. The definition of metabolic abnormality in previous expert statements drew on knowledge of pathophysiology and of study quality to make pragmatic recommendations regarding metabolic thresholds. This more comprehensive review of the literature shows substantial variability, and without the filter of expert interpretation, does not allow identification of consistent thresholds for most of the measured substrates. Finally, complications (or the absence of complications, and the method by which these were recorded) were seldom reported. This is an issue, an issue since the overall number of patients was 2786 and only four patients were reported as having issues secondary to CMD monitoring, leading to concerns about selective harms reporting. In order to undertake a rigorous analysis of complications/harms associated with CMD catheter placement, we also sought evidence for these secondary endpoints in analysis of publications which reported on physiological or imaging endpoints, but provided no data on clinical outcomes. The available evidence suggests that the placement of CMD probes may well be a low-risk procedure $[41,49,50]$, and is accurately reflected by these numbers, but it is impossible to confirm or refute this impression given the available information.

The third critical limitation stems from the focal nature of CMD. Given that the CMD probe only samples a small volume, localized to the tip of the catheter, the results derived from sample analysis provide only insights into focal regional biochemistry. These focal biochemical profiles may not reflect wider, or a more generalized average of, cerebral metabolism. Consequently, inferring relationships between focal CMD biochemistry and global outcomes of interest (functional outcomes, neurophysiology, and/or tissue fate), has significant limitations. However, given the limited ability to accurately measure parenchymal biochemistry and metabolism, we are left with the currently outlined literature base to assess the association between these analytes of interest and various pertinent patient oriented outcomes.

A fourth critical set of limitations was the lack of characterization of patients, especially in many smaller studies. This both contributed to and complicated the limited analysis of differences in CMD findings (and hence outcome associations) in different types of TBI (e.g., diffuse vs. extra-axial hematomas vs. contusions). The location of catheter position and the protocols for CMD sample pooling were not explicitly stated in many studies, and hence make assessment of relationships between monitored variables and outcome relatively crude. In addition, the exact volume of tissue monitored by the CMD probe is not clear, but it is unlikely to be representative of entire regional, hemisphere or global chemistry in the setting of TBI and is likely influenced by injury pattern and treatment. The studies identified within this review fail to delineate injury burden/pattern, and do not address the issue of "focality" of CMD. Thus, our overall conclusions are limited, hence the poor GRADE and RTI assessments for each outcome of interest. The availability of details of ICU management would have provided important insights into the relationships that were observed in some studies and not in 
others, since certain responses to CMD triggers might have impacted outcome while others might not. Further, it is evident that the CMD biochemical pattern varies significantly over time, during the course of disease evolution following TBI. The timing and duration of these abnormal CMD patterns are of importance. It is possible that either very early abnormalities may have import because they dictate the subsequent course of pathophysiology, or that persistent and late emerging abnormalities in the setting of extreme physiologic events (such as refractory ICP) are more related to clinical outcome. However, the current literature identified within this review is not amenable to such temporal profile analysis and thus our comments on such are limited. Such refined analysis of data with knowledge of key variables would substantially add to the richness and reproducibility of any conclusions that we could draw. Indeed, where such data are available, in both small and large studies, they provide important insights into the information provided by CMD [12, 20, 28, 63-65, 84, 93]. However, these data were not consistently available. Such variations, if unbiased, could be seen to replicate the "noise" seen in pragmatic trials and hence not affect the quality of conclusions that are drawn from the data. However, our inability to ensure that this did not result in bias, resulted in a downgrading of the quality of the studies, and was reflected in our overall RTI assessments and GRADE level of evidence associated with each CMD analyte and the outcomes of interest.

Additionally, given that we do not have robust data to suggest/support "normal" values of CMD measured analytes, we cannot make firm comments on the how the "observed" biochemical changes reported within the CMD studies should be interpreted in relation to "normal" human brain values. We unfortunately are limited to commenting on the relationship between CMD analytes in those patients with poor clinical/physiologic progression versus those with good clinical/physiologic progression. It must be acknowledged that those patients with "good" clinical progression in no way represent "normal" CMD analyte values, but merely the values recorded during a desirable clinical or physiologic trajectory. These recorded CMD analyte values are of course subject to the treatments initiated within the ICU. Thus, in order to better understand what we consider "normal" or "acceptable" levels of various CMD analytes in the setting of TBI, large multi-center archived CMD data is required. Only through correlating the trend in these CMD analytes to: injury pattern/burden, clinical course, other multi-modal physiologic monitoring and the treatments implemented, will we be able to more accurately comment on what analyte values are "normal/acceptable" in the setting of TBI, and what values represent secondary deterioration versus treatment effect. Finally, such data sets would potentially allow for more definitive statements regarding the association between common CMD analytes and the outcomes we address in this review.

A fifth critical limitation was the substantial heterogeneity in studies. The included papers varied by study design, prospective versus retrospective nature, number of patients, patient inclusion criteria, ICU-based therapies offered/provided to patients, blinding during outcome assessment, and primary outcome of the studies. Many studies were written with the purpose of describing primary outcomes other than the ones we sought to review, with outcome information for the purpose of this review provided as incidental information. Selective outcome reporting with regards to individual CMD measures and their association to all outcomes of interest was present in most studies, since the focus in many of these studies was to elucidate pathophysiological relationships, rather than seek outcome associations. Thus, the conclusions that can be drawn from such data are limited. Consequently, most CMD measures were deemed to have GRADE C (low), or D (very low), evidence to support of an association. Given these limitations and heterogeneity issues, a meta-analysis could not be performed.

Finally, it is important to acknowledge that the evidence summary and evaluation that we have undertaken relate exclusively to use of CMD as a variable for specific associations (functional outcome, other neurophysiologic measures, and tissue outcome). The more common use of CMD is as a tool for physiological monitoring, to identify downstream consequences of insufficient oxygen and substrate delivery or mitochondrial dysfunction, and trigger changes in management. Indeed, though prognostic thresholds were identified and published based on the data in these papers, in many instances, the primary aim of the relevant studies was to explore pathophysiology and assess response to therapy. Microdialysis monitoring has undoubtedly informed our understanding of the fundamental biology that underpins metabolic failure following TBI, and provided a rational framework for therapy individualization that can be addressed in interventional trials. The current systematic review process does not address these uses of microdialysis. Similarly, the strength of a relationship between a measured CMD variable and functional, or tissue, outcome could be modified by interventions that were triggered by the CMD measurement. The available data did not allow us to explore the modulatory effect of treatment on the relationship between CMD variables and the various outcomes of interest for this review.

\section{Technical standardization of microdialysis technique}

Cerebral microdialysis is a flexible technique, but this leads to an additional complexity in amalgamating data across studies. These issues can be divided into methodological issues, and targeting of tissue at risk. The commonest microdialysis 
catheters used in clinical practice are the CMA $70(20-\mathrm{kDa}$ molecular weight cut off (MWCO)) and CMA 71 (100 kDa MWCO) (CMA Microdialysis AB, Sweden). For the metabolic intermediaries discussed in this review, which are of small molecular weight ( $200 \mathrm{Da})$, the effect of catheter MWCO has little impact on the efficiency of recovery of the molecules of interest [38]. This is not true of CMD for protein biomarkers, but a full discussion of the methodological issues, including alternative perfusion fluids, is outside the scope of this review [35]. The flow rate through the microdialysis catheter also has an impact on the extraction efficiency from the brain ECF, but in clinical applications is typically $0.3 \mu \mathrm{l} / \mathrm{min}$, although much higher flow rates have been used for samples involving rapid sampling in specialized circumstances.

As a focal technique, CMD catheters sample a small region of brain and the location of the tip of the catheter has an impact on the resulting data. In TBI, several approaches have been taken including two catheter studies comparing perilesional and radiologically normal brain on $\mathrm{CT}$, in the same patient [94]. The results from CMD must therefore be interpreted in an individualized fashion based on the position of the microdialysis catheter tip in relation to specific lesions. However, in general, for patients without a focal lesion the catheter is typically inserted into right frontal lobe i.e. non-dominant, noneloquent cortex, and for focal lesions such as a contusion or subdural hematoma, the catheter should be placed in the brain adjacent $(\sim 2 \mathrm{~cm})$ to the focal lesion targeting brain which is 'at risk' but not irretrievably damaged.

\section{Future directions}

There is a large body of literature supporting the association between common CMD measures with both patient functional outcomes and neuro-physiologic measures. This data has provided a basis for pragmatic expert recommendations for use of CMD as a clinical monitoring variable. We confirm these relationships, but our formal assessment of the evidence base suggests many improvements that could be incorporated into the reporting of future studies. We believe that addressing additional factors could provide more robust evidence relating CMD variables to outcome.

First, it seems clear that CMD variables will explain only part of the outcome variation in TBI. This predicates several conclusions. It is likely that large patient numbers will be needed to robustly identify key relationships between CMD and outcome, both overall, and also in selective pathoanatomical groups (e.g. diffuse vs. focal injury). A definitive large multicenter study, focused on CMD, could address this issue, and there is a hope that ongoing prospective studies, including CENTER-TBI [52] and TRACK -TBI [106], may be positioned to answer some of these questions. However, CMD is not part of the core data collection in either of these studies, and patients with CMD monitoring will only represent a minority of the ICU patients recruited. Consequently, it is important that we find ways to make use of all of the data that emerges in this area, including those from smaller studies. We would therefore recommend a common data elements approach to reporting in all CMD studies, with specification of catheter site, location in relation to lesions, type of injury (e.g., by Marshall Grade), CMD thresholds used as triggers in clinical management (ideally as specified by expert consensus statements, while recognizing that these may be different from those used as associations for outcome), and clear documentation of outcome.

Second, it would be useful if the other variables that are known to affect outcome are characterized in publications (with a minimum suggested inclusion of variables that form part of the IMPACT CT model [67, 77, 90, 104]. This would allow us to identify not just the prognostic impact of CMD variable, but also define the supplementary explanatory power that they provide in addition to other well established variables such as GCS and age.

Third, all studies need to explicitly report data that allow assessment of bias. Some of the larger and more rigorous studies in this review explicitly recognized some of these limitations [93], but many neglected to report on these. These data would include the basis on which patients were selected for inclusion, how the study population reflected the broader population of patients in recruiting center, a statement as to whether the outcome assessors were blinded to CMD data, the basis for reporting only some of the CMD variables available, and inclusion of negative results where these are available.

Fourth, to the association between CMD analytes and the three outcome measures we explored needs to be assessed in the context of multimodality monitoring data. Ongoing prospective studies, including CENTER-TBI [52] and TRACK TBI [106], may be best positioned to answer some of these questions. It is unlikely that a single monitoring technique in isolation will prove sufficient to predict physiology and patient/tissue fate. A combination of multi-modal monitoring techniques will we better enable us to understand the extent of injury and ongoing physiologic/metabolic changes, and arguably stand a better chance of enabling more targeted therapy improved patient outcomes. We would encourage funding bodies to mandate such data collection, and also allow funding provision for such data curation so that legacy research can be of high quality.

Fifth, with regards to imaging-based tissue outcome associations, given the likely availability of data from centers of excellence using CMD in the acute phase, and the common use of follow-up imaging in TBI patients, we believe that a retrospective analysis could substantially refine the way we think about and use CMD, and provide guidance for subsequent prospective studies that address the relationship between CMD variables and tissue fate. It is likely, however, that the patient numbers with both acute CMD data and late 
imaging are likely to be a minority of the population recruited to research studies, even in centers of excellence. Consequently, a collaborative analysis of the data across centers is likely to be needed to deliver adequate statistical power. Such an analysis will have to address clear pitfalls, including the amalgamation of imaging data from multiple platforms, better characterization of individual patients in each study to allow for covariate adjustment in combined analysis, and innovative statistical approaches to account for late imaging at variable intervals post-TBI to maximize the number of patients who can be included. We also need to reach consensus on the CMD variables that would be included in such analyses, but given the retrospective, hypotheses setting nature of this exercise, a case can be made for attempting to include the widest range of CMD variables.

Finally, it would be useful to consider what imaging modalities would provide the best assessment of tissue fate in such analysis in prospective studies, and when such tissue fate should be assessed following TBI. The choice of imaging modality is difficult. CT is a poor metric of tissue fate in TBI, but its common (near universal) availability could make it attractive as a measure of global or regional atrophy. However, if being undertaken solely for the purpose of such a research analysis, conventional structural MRI has many advantages, including lack of radiation burden, better parenchymal contrast, the ability to differentiate cortical and white matter loss, and good protocols for combining data from different platforms (partly derived from the dementia imaging literature), especially if control data are also available for individual centers. In fact, it would be possible to relate CMD variables to age calibrated metrics of neuronal loss. Indeed, for the next generation of analyses, many of which will be retrospective, a simple $\mathrm{T} 1$ weighted image could provide an excellent basic assessment. However, future studies need to take account of the fact that tissue injury in TBI may not present just as pan-necrosis, but also as selective neuronal loss, which may be undetectable by conventional MRI. Detection of this process may provide a more sensitive outcome measure of the metabolic abnormalities detected by CMD on one hand, and a more relevant substrate for functional outcome on the other. Selective neuronal loss (SNL) can be detected by diffusion tensor imaging, MRS or $\left[{ }^{11} \mathrm{C}\right]$ flumazenil PET. The first two of these modalities, and DTI in particular, are rapidly gaining currency as routine research imaging techniques, and show promise for future studies in this context. Further to this, the timing of imaging studies may be crucial in achieving maximal sensitivity for imaging to provide a downstream marker of CMD detected physiological stress. While imaging at 6 months is common, a case can be made for earlier imaging assessment in studies that specifically relationships with acute CMD in the first few days and weeks post TBI, since this could avoid the confound provided by late tissue loss caused by later, and more persistent processes such as neuroinflammation. However, we also need to allow time for any imaging changes to evolve. The retrospective analysis that was discussed earlier, and data from ongoing large prospective studies, such as CENTER-TBI [52] and TRACK-TBI [106], which incorporate serial imaging, could provide guidance on this in the future, but a time interval of 2-3 months might provide the best balance between allowing maturation of the impact of acute physiology and minimizing the confound cause by subacute events.

The more rigorous process of data collection and analysis that we describe will allow use to base future inferences on high-quality studies (even if involving smaller numbers of patients), and better inform the identification of key physiological thresholds related to patient functional outcome and imaging based tissue outcomes. Further studies and analyses need to evaluate the link between abnormal CMD monitoring and other multi-modal monitoring parameters, and to subacute/chronic tissue outcomes. Our goal was to outline the literature, comprehensively, and be critical of the rigor and evidence. It is true that the current CMD literature suffers from limitations, leading to some potential uncertainty regarding its clinical application. Not addressing these issues will restrict the quality of inferences we draw from data.

\section{Conclusions}

There currently exists GRADE C evidence to support an association between low CMD measured glucose and poor patient functional outcome at 3-6 months in severe TBI. Similarly, there exists GRADE C evidence to support an association between high CMD measured glutamate, glycerol, lactate, LPR and poor patient functional outcome at 36 months in severe TBI. Furthermore, there currently exists GRADE C level of evidence supporting an association between CMD measured LPR, glutamate and glycerol with ICP and/or CPP. In addition, there currently exists GRADE $\mathrm{C}$ evidence to support an association between $\mathrm{LPR}$ and $\mathrm{PbtO} 2$. All remaining CMD measures displayed either GRADE D evidence, or occasionally no evidence, to support a relationship with physiologic measures. Finally, there currently exists GRADE D evidence to suggest a potential association between elevated CMD measured LPR and frontal lobe atrophy at 6 months post-severe TBI.

All studies reviewed suffer from significant bias, primarily attributable to the primary focus of the individual studies included in this review, which was different from the aims that we sought to explore. Our analysis does not address the use of CMD for characterizing pathophysiology or titrating therapy, and cannot account for any modulation of CMD-outcome relationships by therapy. However they clearly define a role for a new generation of studies analyzing the relationship between common CMD measures and other methods of multi- 
modal monitoring with patient functional outcome. These need to include the technical specification recommended in past expert guidelines and provide appropriate documentation that allows exclusion of bias.

Acknowledgements This work was made possible through salary support through the Cambridge Commonwealth Trust Scholarship, the Royal College of Surgeons of Canada - Harry S. Morton Traveling Fellowship in Surgery, the University of Manitoba Clinician Investigator Program, R. Samuel McLaughlin Research and Education Award, the Manitoba Medical Service Foundation, and the University of Manitoba Faculty of Medicine Dean's Fellowship Fund.

These studies were supported by National Institute for Healthcare Research (NIHR, UK) through the Acute Brain Injury and Repair theme of the Cambridge NIHR Biomedical Research Centre, an NIHR Senior Investigator Award to DKM, and an NIHR Research Professorship to PJAH. Authors were also supported by a European Union Framework Program 7 grant (CENTER-TBI; Grant Agreement No. 602150).

EPT has received funding support from Swedish Society of Medicine (Grant no. SLS-587221).

\section{Compliance with ethical standards}

Disclosures FAZ has received salary support for dedicated research time, during which this project was partially completed. Such salary support came from: the Cambridge Commonwealth Trust Scholarship, the Royal College of Surgeons of Canada - Harry S. Morton Traveling Fellowship in Surgery, the University of Manitoba Clinician Investigator Program, R. Samuel McLaughlin Research and Education Award, the Manitoba Medical Service Foundation, and the University of Manitoba - Faculty of Medicine Dean's Fellowship Fund.

EPT has received funding support from Swedish Society of Medicine (Grant no. SLS-587221).

$\mathrm{MC}$ has financial interest in a part of licensing fee for ICM+ software (Cambridge Enterprise Ltd., UK). Unpaid co-Director of Technicam Ltd.producer of Cranial Access Device used for CMD insertion.

PJAH is the director of Technicam manufacturer of the Technicam Cranial Access Device.

DKM has consultancy agreements and/or research collaborations with GlaxoSmithKline Ltd.; Ornim Medical; Shire Medical Ltd.; Calico Inc.; Pfizer Ltd.; Pressura Ltd.; Glide Pharma Ltd.; and NeuroTraumaSciences LLC.

Open Access This article is distributed under the terms of the Creative Commons Attribution 4.0 International License (http:// creativecommons.org/licenses/by/4.0/), which permits unrestricted use, distribution, and reproduction in any medium, provided you give appropriate credit to the original author(s) and the source, provide a link to the Creative Commons license, and indicate if changes were made.

\section{References}

1. Adamides AA, Rosenfeldt FL, Winter CD, Pratt NM, Tippett NJ, Lewis PM, Bailey MJ, Cooper DJ, Rosenfeld JV (2009) Brain tissue lactate elevations predict episodes of intracranial hypertension in patients with traumatic brain injury. J Am Coll Surg 209(4):531-539

2. Alessandri B, Doppenberg E, Zauner A, Woodward J, Choi S, Bullock R (1999) Evidence for time-dependent glutamate-mediated glycolysis in head-injured patients: a microdialysis study. Acta Neurochir Suppl 75:25-28
3. Alessandri B, Doppenberg E, Zauner A, Woodward J, Young HF, Bullock R (1998) Cortical extracellular sodium transients after human head injury: an indicator of secondary brain damage. Acta Neurochir Suppl 71:237-240

4. Asgari S, Vespa P, Bergsneider M, Hu X (2011) Lack of consistent intracranial pressure pulse morphological changes during episodes of microdialysis lactate/pyruvate ratio increase. Physiol Measure 32(10):1639-1651

5. Asgari S, Vespa P, Hu X (2013) Is there any association between cerebral vasoconstriction/vasodilation and microdialysis lactate to pyruvate ratio increase? Neurocrit Care 19(1):56-64

6. Badenes R, Gonzalez P, Alcover L, Maruenda A, Belda J (2006) Intensive insulin therapy in traumatic brain injury patients: a microdialysis study. Crit Care Med 37(12 Suppl):A46

7. Belli A, Sen J, Petzold A, Russo S, Kitchen N, Smith M (2008) Metabolic failure precedes intracranial pressure rises in traumatic brain injury: a microdialysis study. Acta Neurochir 150(5):461-470

8. Belli A, Sen J, Petzold A, Russo S, Kitchen N, Smith M, Tavazzi B, Vagnozzi R, Signoretti S, Amorini AM, Bellia F, Lazzarino G (2006) Extracellular $N$-acetylaspartate depletion in traumatic brain injury. J Neurochem 96(3):861-869

9. Bidot CJ, Sanchez J, Ponce E, Nemeth Z, Morrison C, O'Phelan K, Jagid J, Olvey S, Hong LF, Bullock R (2011) Microdialysis in severe traumatic brain injury (TBI): cerebral chemistry vs Glasgow outcome scale. J Neurotrauma 28(6):A94

10. Bolcha M, Hejcl A, Prochazka J, Huskova E, Sames M (2014) Elevated intracranial pressure and impaired brain metabolism correlate with fatal outcome after severe brain injury. J Neurotrauma 31(5):A10

11. Bouzat P, Marques-Vidal P, Zerlauth JB, Sala N, Suys T, Schoettker P, Bloch J, Daniel RT, Levivier M, Meuli R, Oddo M (2015) Accuracy of brain multimodal monitoring to detect cerebral hypoperfusion after traumatic brain injury. Crit Care Med 43(2):445-452

12. Bullock R, Zauner A, Woodward JJ, Myseros J, Choi SC, Ward JD, Marmarou A, Young HF (1998) Factors affecting excitatory amino acid release following severe human head injury. $\mathrm{J}$ Neurosurg 89(4):507-518

13. Chamoun R, Suki D, Gopinath SP, Goodman JC, Robertson C (2010) Role of extracellular glutamate measured by cerebral microdialysis in severe traumatic brain injury. J Neurosurg 113(3): 564-570

14. Chan MTV, Ng SCP, Lam JMK, Poon WS, Gin T (2005) Monitoring of autoregulation using intracerebral microdialysis in patients with severe head injury. Acta Neurochir Suppl 95:113-116

15. Chan MT, Ng SC, Lam JM, PoonWS GT (2005) Re-defining the ischemic threshold for jugular venous oxygen saturation - a microdialysis study in patients with severe head injury. Acta Neurochir Suppl 95:63-66

16. Chen J, Gombart Z, Rogers S, Adler D, Sherrill J, Cecil S (2010) A comparison of cerebral microdialysis in elderly versus young patients with traumatic brain injury. Neurocrit Care 13:S171

17. Clausen T, Alves OL, Reinert M, Doppenberg E, Zauner A, Bullock R (2005) Association between elevate brain tissue glycerol levels and poor outcome following severe traumatic brain injury. J Neurosurg 103(2):233-238

18. Clausen T, Khaldi A, Zauner A, Reinert M, Doppenberg E, Menzel M, Soukup J, Alves OL, Bullock MR (2005) Cerebral acid-base homeostasis after severe traumatic brain injury. J Neurosurg 103(4):597-607

19. de Lima Oliveira M, Kairalla AC, Fonoff ET, Martinez RC, Teixeira MJ, Bor-Seng-Shu E (2014) Cerebral microdialysis in traumatic brain injury and subarachnoid hemorrhage: state of the art. Neurocrit Care 21(1):152-162 
20. Dizdarevic K, Hamdan A, Omerhodzic I, Kominlija-Smajic E (2012) Modified Lund concept versus cerebral perfusion pressure-targeted therapy: a randomized controlled study in patients with secondary brain ischaemia. Clin Neurol Neurosurg 114(2):142-148

21. Figaji A, Ross S, Rohlwink U, Fiegeen G, Padayachy L, Hoffman $\mathrm{J}$ (2013) Metabolic and inflammatory changes in the injured brain. Childs Nerv Syst 29(9):1718-1719

22. Filippou M, Alger J, McArthur D, Vespa P (2010) Non-ischemic mitochondrial dysfunction is the most common metabolic abnormality after TBI. Crit Care Med 38:A225

23. Filippou M, Stein NR, Alger J, McArthur DL, Vespa P (2012) Microdialysis lactat/pyruvate ratio correlates with magnetic resonance spectroscopy $N$-acetylaspartate in acute severe traumatic brain injury. J Neurotrauma 29(10):A137

24. Frontera J, Ziai W, O'Phelan K, Leroux PD, Kirkpatrick PJ, Diringer MN, Suarez JI, Second Neurocritical Care Research Conference Investigators (2015) Regional brain monitoring in the neurocritical care unit. Neurocrit Care 22(3):348-359

25. Goodman JC, Valadka AB, Gopinath SP, Uzura M, Robertson CS (1999) Extracellular lactate and glucose alterations in the brain after head injury measured by microdialysis. Crit Care Med 27(9):1965-1973

26. Goodman JC, Valadka AB, Gopinath SP, Cormio M, Roberston CS (1996) Lactate and excitatory amino acids measured by microdialysis are decreased by pentobarbital coma in head-injured patients. J Neurotrauma 13(10):549-556

27. Gopinath SP (1999) Extracellular glutamate and aspartate in head injured patients. Acta Neurochir Suppl 76:409-413

28. Gupta D (2016) A correlative study of ischemic and cell breakdown markers in intraparenchymal traumatic brain injured patients: a cerebral microdialysis correlative study. Int Care Med Exper 4(Suppl):30

29. Gupta DK, Singla R, Kale SS, Sharma BS (2016) Intracerebral hypoglycemia and its clinical relevance as a prognostic indicator in severe traumatic brain injury: a cerebral microdialysis study from India. Neurol India 64(2):259-264

30. Guyatt GH, Oxman AD, Kunz R, Falck-Ytter Y, Vist GE, Liberati A, Schünemann HJ, GRADE Working Group (2008) Rating quality of evidence and strength of recommendations: Going from evidence to recommendations. BMJ 336(7652):1049-1051

31. Guyatt GH, Oxman AD, Kunz R, Jaeschke R, Helfand M, Liberati A, Vist GE, Schünemann HJ, GRADE Working Group (2008) Rating quality of evidence and strength of recommendations: Incorporating considerations of resources use into grading recommendations. BMJ 336(7654):1170-1173

32. Guyatt GH, Oxman AD, Kunz R, Vist GE, Falck-Ytter Y, Schünemann HJ, GRADE Working Group (2008) Rating quality of evidence and strength of recommendations: What is "quality of evidence" and why is it important to clinicians? BMJ 336(7651): 995-998

33. Guyatt GH, Oxman AD, Vist G, Kunz R, Falck-Ytter Y, Alonso-Coello P, Schünemann HJ, GRADE Working Group (2008) Rating quality of evidence and strength of recommendations GRADE: an emerging consensus on rating quality of evidence and strength of recommendations. BMJ 336:924-926

34. Hejcl A, Bolcha M, Prochazka J, Huskova E, Sames M (2012) Elevated intracranial pressure, low cerebra perfusion pressure, and impaired brain metabolism correlate with fatal outcome after severe brain injury. J Neurol Surg A Cent Eur Neurosurg 73(1):10 17
35. Helmy A, Carpenter KL, Skepper JN, Kirkpatrick PJ, Pickard JD, Hutchinson PJ (2009) Microdialysis of cytokines: methodological considerations, scanning electron microscopy, and determination of relative recovery. J Neurotrauma 26(4):549-561

36. Helmy A, Guilfoyle MR, Carpenter KL, Pickard JD, Menon DK, Hutchinson PJ (2016) Recombinant human interleukin-1 receptor antagonist promotes M1 microglia biased cytokines and chemokines following human traumatic brain injury. J Cereb Blood Flow Metab 36(8):1434-1448

37. Higgins JPT, Green S (eds) Cochrane handbook for systematic reviews of interventions version 5.1.0. http:handbook.cochrane. org. Accessed 25 Oct 2015

38. Hutchinson PJ, Al-Rawi PG, O'Connell MT, Gupta AK, Maskell LB, Hutchinson DB, Pickard JD, Kirkpatrick PJ (2000) On-line monitoring of substrate delivery and brain metabolism in head injury. Acta Neurochir Suppl 76:431-435

39. Hutchinson PJ, Gupta AK, Fryer TF, Al-Rawi PG, Chatfield DA, Coles JP, O'Connell MT, Kett-White R, Minhas PS, Aigbirhio FI, Clark JC, Kirkpatrick PJ, Menon DK, Pickard JD (2002) Correlation between cerebral blood flow, substrate delivery, and metabolism in head injury: A combined microdialysis and triple oxygen positron emission tomography study. J Cereb Blood Flow Meta 22(6):735-745

40. Hutchinson PJ, O'Connell MT, Seal A, Nortje J, Timofeev I, AlRawi PG, Coles JP, Fryer TD, Menon DK, Pickard JD, Carpenter KL (2009) A combined microdialysis and FDG-PET study of glucose metabolism in head injury. Acta Neurochir 151(1):51-61

41. Hutchinson PJ, Jalloh I, Helmy A, Carpenter KL, Rostami E, Bellander BM, Boutelle MG, Chen JW, Claassen J, DahyotFizelier C, Enblad P, Gallagher CN, Helbok R, Hillered L, Le Roux PD, Magnoni S, Mangat HS, Menon DK, Nordström CH, O'Phelan KH, Oddo M, Perez Barcena J, Robertson C, RonneEngström E, Sahuquillo J, Smith M, Stocchetti N, Belli A, Carpenter TA, Coles JP, Czosnyka M, Dizdar N, Goodman JC, Gupta AK, Nielsen TH, Marklund N, Montcriol A, O'Connell MT, Poca MA, Sarrafzadeh A, Shannon RJ, Skjøth-Rasmussen J, Smielewski P, Stover JF, Timofeev I, Vespa P, Zavala E, Ungerstedt U (2015) Consensus statement from the 2014 International Microdialysis Forum. Intensive Care Med 41(9): $1517-1528$

42. Igarashi Y, Yokobori S, Fujiki Y, Yamaguchi M, Hashizume A, Onda H, Araki T, Ogawa S, Fuse A, Yokata H (2014) Cerebral extracellular chemistry and outcome of patients with acute subdural hematoma. J Neurotrauma 31(5):A5

43. Jaeschke R, Guyatt GH, Dellinger P, Schünemann H, Levy MM, Kunz R, Norris S, Bion J, GRADE Working Group (2008) Use of GRADE grid to reach decisions on clinical practice guidelines when consensus is elusive. BMJ 337:a744

44. Johnston AJ, Steiner LA, Coles JP, Chatfield DA, Fryer TD, Smielewski P, Hutchinson PJ, O'Connell MT, Al-Rawi PG, Aigbirihio FI, Clark JC, Pickard JD, Gupta AK, Menon DK (2005) Effect of cerebral perfusion pressure augmentation on regional oxygenation and metabolism after head injury. Crit Care Med 33(1):189-195

45. Karanthanou A, Paterakis K, Pakopoulou M, Tasiou A, Hadjigeorgiou G, Chovas A (2011) Biochemical markers analyzed using microdialysis and traumatic brain injury outcomes. J Neurosurg Sci 55(3):173-177

46. Kitagawa R, Yokobori S, Mazzeo AT, Bullock R (2013) Microdialysis in the neurocritical care unit. Neurosurg Clin N Am 24(3):417-426

47. Koura SS, Doppenberg EM, Marmarou A, Choi S, Young HF, Bullock R (1998) Relationship between excitatory amino acid 
release and outcome after severe human head injury. Acta Neurochir Suppl 71:244-246

48. Kurtz P, Claassen J, Schmidt JM, Helbok R, Hanafy KA, Presciutti M (2013) Reduced brain/serum glucose ratios predict cerebral metabolic distress and mortality after severe brain injury. Neurocrit Care 19(3):311-319

49. Le Roux P, Menon DK, Citerio G, Vespa P, Bader MK, Brophy G, Diringer MN, Stocchetti N, Videtta W, Armonda R, Badjatia N, Bösel J, Chesnut R, Chou S, Claassen J, Czosnyka M, De Georgia M, Figaji A, Fugate J, Helbok R, Horowitz D, Hutchinson P, Kumar M, McNett M, Miller C, Naidech A, Oddo M, Olson D, O’Phelan K, Provencio JJ, Puppo C, Riker R, Roberson C, Schmidt M, Taccone F (2014) Consensus summary statement of the International Multidisciplinary Consensus Conference on Multimodality Monitoring in Neurocritical Care: a statement for healthcare professionals from the Neurocritical Care Society and the European Society of Intensive Care Medicine. Neurocrit Care 21(Suppl 2):S1-26

50. Le Roux P, Menon DK, Citerio G, Vespa P, Bader MK, Brophy GM, Diringer MN, Stocchetti N, Videtta W, Armonda R, Badjatia N, Böesel J, Chesnut R, Chou S, Claassen J, Czosnyka M, De Georgia M, Figaji A, Fugate J, Helbok R, Horowitz D, Hutchinson P, Kumar M, McNett M, Miller C, Naidech A, Oddo M, Olson D, O'Phelan K, Provencio JJ, Puppo C, Riker R, Robertson C, Schmidt M, Taccone F, Society NC, European Society of Intensive Care Medicine (2014) Consensus summary statement of the International Multidisciplinary Consensus Conference on Multimodality Monitoring in Neurocritical Care: a statement for healthcare professionals from the Neurocritical Care Society and the European Society of Intensive Care Medicine. Intensive Care Med 40(9):1189-1209

51. Li AL, Zhi DS, Wang Q, Huang HL (2008) Extracellular glycerol in patients with severe traumatic brain injury. Chin J Traumatol 11(2):84-88

52. Maas AI, Menon DK, Steyerberg EW, Citerio G, Lecky F, Manley GT, Hill S, Legrand V, Sorgner A, CENTER-TBI Participants and Investigators (2015) Collaborative European NeuroTrauma Effectiveness Research in Traumatic Brain Injury (CENTERTBI): a prospective longitudinal observational study. Neurosurgery 76(1):67-80

53. Marcoux J, McArthur DA, Miller C, Glenn TC, Villablanca P, Martin NA, Hovda DA, Alger JR, Vespa PM (2008) Persistent metabolic crisis as measure by elevated cerebral microdialysis lactate-pyruvate ratio predicts chronic frontal lobe brain atrophy after traumatic brain injury. Crit Care Med 36(10):2871-2877

54. Mazzeo AT, Kunene NK, Choi S, Gilman C, Bullock RM (2006) Quantitation of ischemic events after severe traumatic brain injury in humans: a simple scoring system. J Neurosurg Anesthesiol 18(3): 170-178

55. Mellergard P, Sjogren F, Hillman J (2012) The cerebral extracellular release of glycerol, glutamate, and FGF2 is increased in older patients following severe traumatic brain injury. J Neurotrauma 29(1):112-118

56. Meixensberger J, Junze E, Barcsay E, Vaeth A, Roosen K (2001) Clinical cerebral microdialysis: brain metabolism and brain tissue oxygenation after acute brain injury. Neurol Res 23(8):801-806

57. Menzel M, Doppenberg EMR, Zauner A, Soukup J, Reinert MM, Bullock R (1999) Increased inspired oxygen concentration as a factor in improved brain tissue oxygenation and tissue lactate levels after severe human head injury. J Neurosurg 91(1):1-10

58. Menzel M, Doppenberg EMR, Zauner A, Soukup J, Reinert MM, Clausen T, Brockenbrough PB, Bullock R (1999) Cerebral oxygenation in patients after severe head injury: monitoring and effects of arterial hyperoxia on cerebral blood flow, metabolism, and intracranial pressure. J Neurosurg Anesthesiol 11(4):240-251

59. Moher D, Liberati A, Tetzlaff J, Altman DG, PRISMA Group (2009) Preferred reporting items for systematic reviews and metaanalysis: the PRISMA statement. Ann Intern Med 151(4):264-269

60. Nelson DW, Bellander BM, MacCallum RM, Axelsson J, Alm M, Wallin M, Weitzberg E, Rudehill A (2004) Cerebral microdialysis of patients with severe traumatic brain injury exhibits highly individualistic patterns as visualized by cluster analysis with self-organizing. Crit Care Med 32(12):2428-2436

61. Nelson DW, Thornquist B, MacCallum RM, Nyström H, Holst A, Rudehill A, Wanecek M, Bellander BM, Weitzberg E (2011) Analysis of cerebral microdialysis in patients with traumatic brain injury: relations to intracranial pressure, cerebral perfusion pressure and catheter placement. BMC Med 9:21

62. Nordstrom CH, Nielsen TH, Schalen W, Reinstrup P, Ungerstedt $\mathrm{U}$ (2016) Biochemical indications of cerebral ischaemia and mitochondrial dysfunction in severe brain trauma analyzed with regard to type of lesion. Acta Neurochir 158(7):1231-1240

63. Nortje J, Coles JP, Timofeev I, Fryer TD, Aigbirhio FI, Smielewski P, Outtrim JG, Chatfield DA, Pickard JD, Hutchinson PJ, Gupta AK, Menon DK (2008) Effect of hyperoxia on regional oxygenation and metabolism after severe traumatic brain injury: preliminary findings. Crit Care Med 36(1):273-281

64. Oddo M, Schmidt JM, Carrera E, Badjatia N, Connolly ES, Presciutti M, Ostapkovich ND, Levine JM, Le Roux P, Mayer SA (2008) Impact of tight glycemic control on cerebral glucose metabolism after severe brain injury: a microdialysis study. Crit Care Med 36(12):3233-3238

65. Olivecrona M, Rodling-Wahlstrom M, Naredi S, Koskinen LOD (2009) Prostacyclin treatment in severe traumatic brain injury: a microdialysis and outcome study. J Neurotrauma 26(8):1251-1262

66. Omerhodzic I, Dizdarevic K, Rotim K, Hajdarpasić E, Niksić M, Bejtić-Custović E, Selimović E, Custović M (2011) Cerebral microdialysis: perioperative monitoring and treatment of severe neurosurgical patient. Acta Clin Croat 50(1):13-20

67. Panczykowski DM, Puccio AM, Scruggs BJ, Baue JS, Hricik AJ, Beer SR, Okonkwo DO (2012) Prospective independent validation of IMPACT modeling as a prognostic tool in severe traumatic brain injury. J Neurotrauma 29:47-52

68. Papinkolaou PG, Barkas K, Barthouniotou E, Pabukos S, Zogbi H, Georgoulis G, Rizikari M, Damilakis K, Voidonikolas L, Kyriakou T, Katsaris G (2009) Brain tissue glycerol levels in severe brain trauma - a series of 30 patients. Intensive Care Med 35:S74

69. Paraforou T, Paterakis K, Fountas K, Paraforos G, Chovas A, Tasiou A, Mpakopoulou M, Papadopoulos D, Karavellis A, Komnos A (2011) Cerebral perfusion pressure, microdialysis biochemistry and clinical outcome in patients with traumatic brain injury. BMC Res Notes 4:540

70. Peerdeman SM, Girbes ARJ, Polderman KH, Vandertop WP (2003) Changes in cerebral interstitial glycerol concentration in head-injured patients: correlation with secondary events. Intensive Care Med 29(10):1825-1828

71. Petzold A, Tisdall MM, Girbes AR, Martinian L, Thom M, Kitchen N, Smith M (2011) In vivo monitoring of neuronal loss in traumatic brain injury: a microdialysis study. Brain 134(Part 2): 464-483

72. Purins K, Lewen A, Hillered L, Howells T, Enblad P (2014) Brain tissue oxygenation and cerebral metabolic patterns in focal and diffuse traumatic brain injury. Front Neurol 5:64

73. Reinert M, Andres RH, Fuhrer M, Muller A, Schaller B, Widmer $\mathrm{H}$ (2007) Online correlation of spontaneous arterial and 
intracranial pressure fluctuations in patients with diffuse severe head injury. Neurol Res 29(5):455-462

74. Reinert M, Khaldi A, Zauner A, Doppenberg E, Choi S, Bullock R (2000) High level of extracellular potassium and its correlates after severe head injury: relationship to high intracranial pressure. J Neurosurg 93(5):800-807

75. Richards DA, Tolias CM, Sgouros S, Bower NG (2003) Extracellular glutamine to glutamate ratio may predict outcome in the injured brain: a clinical microdialysis study in children. Pharmacol Res 48(1):101-109

76. Robertson CS, Valadka AB, Goodman JC, Chacko A, Mizutani Y, Howard L (1999) Extracellular concentrations of glutamate and aspartate in the injured brain measured by microdialysis. Crit Care Med 27(Suppl 1):27A-182A

77. Roozenbeek B, Chiu YL, Lingsma HF, Gerber LM, Steyerberg EW, Ghajar J, Maas AI (2012) Predicting 14-day mortality after severe traumatic brain injury: application of the IMPACT models in the brain trauma foundation TBI-trac(R) New York State database. J Neurotrauma 29:1306-1312

78. Sala N, Suys T, Zerlauth JB, Bouzat P, Messerer M, Bloch J, Levivier M, Magistretti PJ, Meuli R, Oddo M (2013) Cerebral extracellular lactate increase is predominantly nonischemic in patients with severe traumatic brain injury. J Cereb Blood Flow Metab 33(11):1815-1822

79. Salci K, Nilsson P, Howells T, Ronne-Engström E, Piper I, Contant CF Jr, Enblad P (2006) Intracerebral microdialysis and intracranial compliance monitoring of patients with traumatic brain injury. J Clin Monit Comput 20(1):25-31

80. Sanchez JJ, Bidot CJ, O'Phelan K, Gajavelli S, Yokobori S, Olvey S, Jagid J, Garcia JA, Nemeth Z, Bullock R (2013) Neuromonitoring with microdialysis in severe traumatic brain injury patients. Acta Neurochir Suppl 118:223-227

81. Sanchez-Porras R, Santos E, Czosnyka M, Zheng Z, Unterberg AW, Sakowitz OW (2012) 'Long' pressure reactivity index (LPRx) as a measure of autoregulation correlates with outcome in traumatic brain injury patients. Acta Neurochir 154(9):1575-1881

82. Sarrafzadeh A, Unterberg A, Lanksch W (1999) Cerebral on-line microdialysis (MD) in neurointensive care: diagnostic implications. Crit Care Med 27(Suppl):27A-182A

83. Sarrafzadeh AS, Sakowitz OW, Callsen TA, Lanksch WR, Unterberg AW (2000) Bedside microdialysis for early detection of cerebral hypoxia in traumatic brain injury. Neurosurg Focus 9(5):e2

84. Sarrafzadeh AS, Salowitz OW, Callsen TA, Lanksch WR, Unterberg AW (2002) Detection of secondary insults by brain tissue $\mathrm{pO} 2$ and bedside microdialysis in severe head injury. Acta Neurochir Suppl 81:319-321

85. Schünemann HJ, Oxman AD, Brozek J, Glasziou P, Jaeschke R, Vist GE, Williams JW Jr, Kunz R, Craig J, Montori VM, Bossuyt P, Guyatt GH, GRADE Working Group (2008) Grading quality of evidence and strength of recommendations for diagnostic tests and strategies. BMJ 336(7653):1106-1110

86. Singla R, Gupta D, Borkar SA, Suri A, Kale SS, Sharma BS (2016) Cerebral perfusion pressure in severe traumatic brain injury and its relation to microdialysis-assessed interstitial brain glycerol and lactate-pyruvate ratio. Indian J Neurotrauma 13(2):59-65

87. Stahl N, Mellergard P, Hallstrom A, Ungerstedt U, Nordstrom CH (2001) Intracerebral microdialysis and bedside biochemical analysis in patients with fatal traumatic brain lesions. Acta Anesthesiol Scand 45(8):977-985

88. Stein NR, McArthur DL, Etchepare M, Vespa PM (2012) Early cerebral metabolic crisis after TBI influences outcome despite adequate hemodynamic resuscitation. Neurocrit Care 17(1):49-57

89. Stein NR, Alger JR, McArthur DL, Tubi MA, Vespa PM (2013) Cerebral metabolic crisis is present following severe TBI despite normal adc values in the microdialysis probe. Neurocrit Care 1(Suppl):S98

90. Steyerberg EW, Mushkudiani N, Perel P, Butcher I, Lu J, McHugh GS, Murray GD, Marmarou A, Roberts I, Habbema JDF, Maas AI (2008) Predicting outcome after traumatic brain injury: development and international validation of prognostic scores based on admission characteristics. PLoS Med 5:e165

91. Stiefel MF, Stoller C, Wainwright JV, Rachel L, Wang A, Marini CP (2015) Cerebral metabolism and physiological parameters vary between survivors and non-survivors of severe traumatic brain injury. Neurocrit Care 1(Suppl):1-289

92. Thelin EP, Nelson DW, Ghatan PH, Bellander BM (2014) Microdialysis monitoring of CSF parameters in severe traumatic brain injury patients: a novel approach. Front Neurol 5:159

93. Timofeev I, Carpenter KLH, Nortje J, Al-Rawi PG, O'Connell MT, Czosnyka M, Smielewski P, Pickard JD, Menon DK, Kirkpatrick PJ, Gupta AK, Hutchinson PJ (2011) Cerebral extracellular chemistry and outcome following traumatic brain injury: a microdialysis study of 223 patients. Brain 134(Part 2):484-494

94. Timofeev I, Czosnyka M, Carpenter KL, Nortje J, Kirkpatrick PJ, Al-Rawi PG, Menon DK, Pickard JD, Gupta AK, Hutchinson PJ (2011) Interaction between brain chemistry and physiology after traumatic brain injury: impact of autoregulation and microdialysis catheter location. J Neurotrauma 28(6):849-860

95. Timofeev I, Nortje J, Al-Rawi PG, Hutchinson PJA, Gupta AK (2013) Extracellular brain $\mathrm{pH}$ with or without hypoxia is a marker of profound metabolic derangement and increased mortality after traumatic brain injury. J Cereb Blood Flow Metab 33(3):422-427

96. Valdaka AB, Goodman JC, Gopinath SP, Uzura M, Roberston CS (1998) Comparison of brain tissue oxygen tension to microdialysis-based measures of cerebral ischemia in fatally head-injured humans. J Neurotrauma 15(7):509-519

97. Vespa P, Bergsenider M, Hattori N, Wu HM, Huang SC, Martin NA, Glenn TC, McArthur DL, Hovda DA (2005) Metabolic crisis without brain ischemia is common after traumatic brain injury: a combined microdialysis and positron emission tomography study. J Cereb Blood Flow Metab 25(6):763-774

98. Vespa P, Prins M, Ronne-Engstrom E, Caron M, Shalmon E, Hovda DA, Martin NA, Becker DP (1998) Increase in extracellular glutamate caused by reduced cerebral perfusion pressure and seizures after human traumatic brain injury: a microdialysis study. J Neurosurg 89(6):971-982

99. Vespa PM, McArthus D, O'Phelan K, Glenn T, Etchepare M, Kelly D, Bergsneider M, Martin NA, Hovda DA (2003) Persistently low extracellular glucose correlates with poor outcome 6 months after human traumatic brain injury despite a lack of increased lactate: a microdialysis study. J Cereb Blood Flow Metab 23(7):865-877

100. Vespa PM, O'Phelan K, McArthur D, Miller C, Eliseo M, Hirt D, Glenn T, Hovda DA (2007) Pericontusional brain tissue exhibits persistent elevation of lactate/pyruvate ratio independent of cerebral perfusion pressure. Crit Care Med 35(4):1153-1160

101. Vilalta A, Sahuquillo J, Merino MA, Poca MA, Garnacho A, Martínez-Valverde T, Dronavalli M (2011) Normobaric hyperoxia in traumatic brain injury: does brain metabolic state influence the response to hyperoxic challenge? J Neurotrauma 28(7):1139-1148

102. Viswanathan M, Berkman ND. (2011) Development of the RTI Item Bank on Risk of Bias and Precision of Observational Studies. Methods Research Report. (Prepared by the RTI InternationalUniversity of North Carolina Evidence-based Practice Center under Contract No. 290-2007-0056-I.) AHRQ Publication No. 11EHC028-EF. Rockville, MD: Agency for Healthcare Research and Quality. Available at: www.effectivehealthcare.ahrq.gov/ reports/final.cfm. Accessed 1 Oct 2016

103. Wang E, King N, Ang BT, Ng I (2009) Improvement in cerebral metabolism is associated with good outcome after decompressive 
craniectomy for severe traumatic brain injury. J Neurotrauma 26(8):A66

104. Yeoman P, Pattani H, Silcocks P, Owen V, Fuller G (2011) Validation of the IMPACT outcome prediction score using the Nottingham Head Injury Register dataset. J Trauma 71:387-392

105. Yokobori S, Watanabe A, Matsumoto G, Onda H, Masuno T, Fuse A, Kushimoto S, Yokota H (2011) Time course of recovery from cerebral vulnerability after severe traumatic brain injury: a microdialysis study. J Trauma 71(5):1235-1240

106. Yue JK, Vassar MJ, Lingsma HF, Cooper SR, Okonkwo DO, Valadka AB, Gordon WA, Maas AI, Mukherjee P, Yuh EL, Puccio AM, Schnyer DM, Manley GT, TRACK-TBI Investigators (2013) Transforming research and clinical knowledge in traumatic brain injury pilot: multicenter implementation of the common data elements for traumatic brain injury. J Neurotrauma 30(22):1831-1844

107. Zauner A, Doppenberg E, Woodward JJ, Allen C, Jebraili S, Young HF, Bullock R (1997) Multiparametric continuous monitoring of brain metabolism and substrate delivery in neurosurgical patients. Neurol Res 19(3):265-273

108. Zauner A, Doppenberg EMR, Woodward JJ, Choi SC, Young HG, Bullock R (1997) Continuous monitoring of cerebral substrate delivery and clearance: initial experience in 24 patients with severe acute brain injuries. Neurosurgery 41(5):1082-1093

109. Zauner A, Bullock R, Kuta AJ, Woodward J, Young HF (1996) Glutamate release and cerebral blood flow after severe human head injury. Acta Neurochir Suppl 67:40-44

\section{Comments}

Zeiler and co-workers provide an extensive review about cerebral microdialysis and outcome in traumatic brain injury. In contrast to many other papers, the authors also included meeting proceedings. I do not think that this is a problem; much more, it is problematic that duplicates could not exactly be eliminated. However, the authors have adequately discussed this limitation and the other limitations of the paper. Most of these limitations are methods immanent limitations of cerebral microdialysis and have to be kept in mind whenever interpreting the results of this method in neuro-intensive-care patients as well as in animal studies.

Marcus Reinges.

Giessen, Germany. 